\title{
7 RESULTADOS DEL ESTUDIO EMPÍRICO
}

En el presente capítulo describiremos los resultados del trabajo empírico realizado. Estos resultados se han agrupado en diferentes fases de acuerdo con las cuatro hipótesis formuladas ${ }^{1}$. Las fases son las siguientes:

1. Comparación interna o individualizada entre todos los actores del Sistema Sanitario Público Catalán. Para estudiar la producción científica y la competitividad entre ellos se han comparado sus resultados de actividad científica, número de otras publicaciones número de personal de nivel superior y valor del presupuesto económico.

2. Comparación interna o individualizada entre las Regiones Sanitarias del Servei Català de la Salut. Para este estudio se analizó la aportación científica que hacen las regiones sanitarias al sistema, comparando su actividad científica y número de otras publicaciones.

3. Comparación interna o individualizada entre las Empresas Públicas del Servei Català de la Salut. Para este estudio se analizó la aportación de actividad científica, el número de otras publicaciones, número de personal de nivel superior y el presupuesto económico.

4. Comparación interna o individualizada entre los hospitales de alta tecnología -Grupo 4- del SI. Conjuntamente estos actores dominan la producción científica del SI-SSPC, además, mantienen un alto grado de rivalidad y competitividad. Para este estudio se analizó la aportación de actividad científica, presupuesto económico,

1 Como en el capítulo 3, pp. 107-131, de este estudio, se han descrito ampliamente las variables, el periodo de tiempo analizado, las fuentes documentales, las técnicas de análisis utilizadas, el marco teórico, las hipótesis, los objetivos y la metodología de la investigación empírica los obviaremos ahora para no caer en repeticiones innecesarias. 
número de camas, número de personal de nivel superior, número de MIR, número de alumnos de medicina, número de publicaciones SCI y su factor de impacto, número de otras publicaciones, número de tesis doctorales, número de proyectos de investigación, número de ensayos clínicos y el número de transplantes que hacen cada uno de los hospitales de alta tecnología del sistema.

5. Análisis de los datos cualitativos de la encuesta hecha a los actores del SI-PSC, estos datos corresponden a las preguntas de la parte 4 de la encuesta.

En cada apartado del capítulo se describen los resultados de cada fase del trabajo y su interpretación para verificar nuestras hipótesis y en el último apartado presentamos la conclusión de todo el trabajo empírico.

Se han excluido del estudio empírico las Empresas Públicas Energética d'Instal.lacions Sanitàries, S.A., Gestió de Serveis Sanitaris, Gestió i Prestació de Serveis de Salut y el Institut d'Assistència Sanitaria por los motivos de escasa actividad de $\mathrm{I}+\mathrm{D}$ y actividad científica divulgadora y por pertenencia, las últimas tres, a hospitales no incluidos en el Grupo 4.

\subsection{FASE 1. ANÁLISIS COMPARATIVO ENTRE TODOS LOS ACTORES DEL SISTEMA SANITARIO PÚBLICO CATALÁN}

Las hipótesis a contrastar en esta fase son las siguientes:

1.1. El valor del presupuesto económico se relaciona significativamente con el número de publicaciones y de actividad científica que generan los actores del sistema.

1.2. El número de personal de nivel superior se relaciona significativamente con el número de publicaciones y de actividad científica que generan los actores del sistema. 
TABLA 7.1. Resumen de las variables analizadas en esta fase.

\begin{tabular}{||l|l||}
\hline Variable & Descripción de la variable \\
\hline \hline Presupuesto económico & $\begin{array}{l}\text { Se obtuvo a partir del presupuesto anual asignado } \\
\text { a los actores del estudio. }\end{array}$ \\
\hline \hline Personal de nivel superior & $\begin{array}{l}\text { Se obtuvo a partir del total de profesionales de } \\
\text { nivel superior de la plantilla de cada uno de los } \\
\text { actores. }\end{array}$ \\
\hline \hline Actividad científica & $\begin{array}{l}\text { Se obtuvo a partir de la suma de la actividad } \\
\text { científica divulgadora, participación u organización } \\
\text { de congresos nacionales e internacionales, } \\
\text { simposios, cursos, jornadas, conferencias, actos, } \\
\text { seminarios y otros [no se incluye en esta variable } \\
\text { las publicaciones SCI u otras publicaciones que } \\
\text { producen los actores del sistema y que son } \\
\text { analizadas por separado]. }\end{array}$ \\
\hline \hline $\begin{array}{l}\text { Publicaciones de libros, } \\
\text { capítulos de libros y demás } \\
\text { publicaciones - otras } \\
\text { publicaciones- }\end{array}$ & $\begin{array}{l}\text { Se obtuvo a partir del número de publicaciones } \\
\text { efectuadas por los actores del estudio [se incluye } \\
\text { en esta variable todas las demás publicaciones } \\
\text { producidas por los actores del SI-SSPC } \\
\text { excluyendo las publicaciones SCI]. }\end{array}$ \\
\hline \hline
\end{tabular}

Fuente: Elaboración propia. 


\subsubsection{RESULTADO Y DESCRIPCIÓN DE LAS TABLAS}

Resultados de la generación de publicaciones y de actividad científica de todos los actores del sistema.

TABLA 7.2. Resultados del presupuesto económico y del número de personal de nivel superior de todos los actores.

\begin{tabular}{|l|c|c|c|c|}
\hline Actor & $\begin{array}{c}\text { Presupuesto } \\
\text { económico }\end{array}$ & \% sobre el total & $\begin{array}{c}\text { Personal de nivel } \\
\text { superior }\end{array}$ & \% sobre el total \\
\hline RSL & 28.106 .056 .830 & 1,8 & 884 & 2,9 \\
\hline RST & 39.727 .530 .490 & 2,5 & 1049 & 3,5 \\
\hline RSTO & 11.531 .624 .900 & 0,7 & 345 & 1,1 \\
\hline RSG & 43.186 .086 .350 & 2,8 & 1258 & 4,1 \\
\hline RSCP & 103.483 .312 .200 & 6,7 & 2982 & 9,8 \\
\hline RSBNM & 57.364 .925 .400 & 3,7 & 1609 & 5,3 \\
\hline RSC & 101.558 .607 .500 & 6,5 & 3600 & 11,8 \\
\hline RSBC & 200.003 .487 .700 & 12,9 & 5870 & 19,3 \\
\hline IDI & 1.588 .521 .975 & 0,10 & 42 & 0,14 \\
\hline SEMSA & 316.183 .755 & 0,02 & 39 & 0,13 \\
\hline AATM & 181.595 .294 & 0,01 & 10 & 0,03 \\
\hline ICO & 3.500 .000 .000 & 0,22 & 80 & 0,26 \\
\hline SSRCTBT & 1.407 .386 .332 & 0,09 & 18 & 0,06 \\
\hline SCS & 603.378 .930 .232 & 38,9 & 574 & 1,9 \\
\hline ICS & 210.480 .414 .000 & 13,6 & 8173 & 26,9 \\
\hline IES & 471.984 .645 & 0,03 & 17 & 0,06 \\
\hline CSUB & 23.608 .228 .000 & 1,5 & 698 & 2,3 \\
\hline HUGTIP & 13.024 .180 .000 & 0,8 & 241 & 0,8 \\
\hline HC & 40.525 .502 .000 & 1,9 & 757 & 2,5 \\
\hline HSJD & 7.787 .701 .000 & 0,5 & 224 & 0,7 \\
\hline HSCSP & 21.650 .800 .000 & 1,4 & 525 & 1,7 \\
\hline CSUVH & 45.192 .332 .000 & 2,9 & 1335 & 4,4 \\
\hline FP & 4.500 .000 .000 & 0,3 & 70 & 0,2 \\
\hline TOTAL & 1.562 .575 .390 .603 & 100,00 & 30400 & 100,00 \\
\hline & & & & \\
\hline & & 10 & & \\
\hline
\end{tabular}

Fuente: Encuesta, preguntas 1 y 4. Número de respuestas: 46.

Del total del presupuesto económico de los actores estudiados destaca el SCS con el 38,9\% seguido por el ICS con el 13,6\% del total del presupuesto. En cuanto al personal de nivel superior se destaca el ICS con el $26,9 \%$ seguido por la RSBC con el 19,3\%. 
TABLA 7.3. Resultados de la actividad científica y de las publicaciones generadas por los actores del sistema.

\begin{tabular}{|l|c|c|c|c|}
\hline Actor & Actividad científica & \% sobre el total & Otras publicaciones & \% sobre el total \\
\hline RSL & 23 & 0,3 & 4 & 0,2 \\
\hline RST & 8 & 0,1 & 4 & 0,2 \\
\hline RSTO & 25 & 0,4 & 7 & 0,4 \\
\hline RSG & 18 & 0,3 & 9 & 0,5 \\
\hline RSCP & 17 & 0,2 & 8 & 0,5 \\
\hline RSBNM & 54 & 0,8 & 5 & 0,3 \\
\hline RSC & 8 & 0,1 & 2 & 0,1 \\
\hline RSBC & 17 & 0,2 & 3 & 0,2 \\
\hline IDI & 951 & 14,6 & 29 & 1,7 \\
\hline SEMSA & 58 & 0,9 & 16 & 1,0 \\
\hline AATM & 114 & 1,8 & 13 & 0,8 \\
\hline ICO & 578 & 10,4 & 109 & 6,5 \\
\hline SSRCTBT & 57 & 0,9 & 13 & 0,8 \\
\hline SCS & 5 & 0,1 & 225 & 13,5 \\
\hline ICS & 114 & 0,1 & 187 & 11,2 \\
\hline IES & 744 & 1,8 & 8 & 0,5 \\
\hline CSUB & 761 & 11,4 & 103 & 6,2 \\
\hline HUGTiP & 530 & 8,1 & 105 & 6,3 \\
\hline HC & 485 & 7,4 & 361 & 21,7 \\
\hline HSJD & 463 & 7,1 & 134 & 8,0 \\
\hline HSCSP & 1079 & 16,6 & 113 & 6,8 \\
\hline CSUVH & 4,2 & 103 & 6,2 \\
\hline FP & 100,0 & 1667 & 6,4 \\
\hline TOTAL & & & 100,0 \\
\hline
\end{tabular}

Fuente: Encuesta, preguntas 6 y 14. Número de respuestas: 46.

Del total de la actividad científica se destacan los hospitales de la Vall d'Hebron con el 16,6\% seguidos por el IDI con el 14,6\% y del total de otras publicaciones se destaca el hospital Clínic con el 21,7\% seguido por el SCS con el 13,5\%. 
TABLA 7.4. Resultados de la actividad científica por presupuesto y personal de nivel superior.

\begin{tabular}{|l|c|c|c|c|c|}
\hline Actor & $\begin{array}{c}\text { Actividad } \\
\text { científica }\end{array}$ & $\begin{array}{c}\text { Presupuesto } \\
\text { económico* }\end{array}$ & $\begin{array}{c}\text { AC/ } \\
\text { presupuesto }\end{array}$ & $\begin{array}{c}\text { Personal de } \\
\text { nivel superior }\end{array}$ & $\begin{array}{c}\text { AC/ personal } \\
\text { nivel superior }\end{array}$ \\
\hline RSL & 23 & 28106 & 0,000818 & 884 & 0,026018 \\
\hline RST & 8 & 39728 & 0,000201 & 1049 & 0,007626 \\
\hline RSTO & 25 & 11532 & 0,002168 & 345 & 0,072464 \\
\hline RSG & 18 & 43186 & 0,000417 & 1258 & 0,014308 \\
\hline RSCP & 17 & 103483 & 0,000164 & 2982 & 0,005701 \\
\hline RSBNM & 54 & 57365 & 0,000941 & 1609 & 0,033561 \\
\hline RSC & 8 & 101559 & 0,000079 & 3600 & 0,002222 \\
\hline RSBC & 17 & 200003 & 0,000085 & 5870 & 0,002896 \\
\hline IDI & 951 & 1589 & 0,598670 & 42 & 22,64286 \\
\hline SEMSA & 58 & 316 & 0,183438 & 39 & 1,487179 \\
\hline AATM & 114 & 182 & 0,627770 & 10 & 11,40000 \\
\hline ICO & 678 & 3500 & 0,193714 & 80 & 8,475000 \\
\hline SSRCTBT & 57 & 1407 & 0,040501 & 18 & 3,166667 \\
\hline SCS & 5 & 603379 & 0,000008 & 574 & 0,008711 \\
\hline ICS & 8 & 210480 & 0,000038 & 8173 & 0,000979 \\
\hline IES & 114 & 472 & 0,241533 & 17 & 6,705882 \\
\hline CSUB & 744 & 23608 & 0,031514 & 698 & 1,065903 \\
\hline HUGTiP & 761 & 13024 & 0,058430 & 241 & 3,157676 \\
\hline HC & 530 & 28752 & 0,013078 & 757 & 0,700132 \\
\hline HSJD & 485 & 7788 & 0,062278 & 224 & 2,165179 \\
\hline HSCSP & 463 & 21651 & 0,021385 & 525 & 0,881905 \\
\hline CSUVH & 1079 & 45192 & 0,023876 & 1335 & 0,808240 \\
\hline FP & 275 & 4500 & 0,061111 & 70 & 3,928571 \\
\hline$*$ Presupuesto & económico expresado en millones de pesetas. & & \\
\hline & & & & & \\
\hline
\end{tabular}

Fuente: Encuesta, preguntas 6, 4 y 1. Número de respuestas: 69.

En esta tabla se observa que el mayor número de actividad científica tienen los hospitales de la Vall d'Hebron, el mayor presupuesto el SCS y el mayor número de personal de nivel superior el ICS. Con relación al índice actividad científica-presupuesto la AATM tiene el mayor índice y con relación al índice actividad científica - personal de nivel superior el IDI tiene el mayor índice. 
TABLA 7.5. Resultados de otras publicaciones por presupuesto y personal de nivel superior.

\begin{tabular}{|l|c|c|c|c|c|}
\hline Actor & $\begin{array}{c}\text { Otras } \\
\text { publicaciones }\end{array}$ & $\begin{array}{c}\text { Presupuesto } \\
\text { económico* }\end{array}$ & $\begin{array}{c}\text { OP / } \\
\text { presupuesto }\end{array}$ & $\begin{array}{c}\text { Personal de } \\
\text { nivel superior }\end{array}$ & $\begin{array}{c}\text { OP / personal } \\
\text { nivel superior }\end{array}$ \\
\hline RSL & 4 & 28106 & 0,000142 & 884 & 0,004525 \\
\hline RST & 4 & 39728 & 0,000101 & 1049 & 0,003813 \\
\hline RSTO & 7 & 11532 & 0,000607 & 345 & 0,020290 \\
\hline RSG & 9 & 43186 & 0,000208 & 1258 & 0,007154 \\
\hline RSCP & 8 & 103483 & 0,000077 & 2982 & 0,002683 \\
\hline RSBNM & 5 & 57365 & 0,000087 & 1609 & 0,003108 \\
\hline RSC & 2 & 101559 & 0,000020 & 3600 & 0,000556 \\
\hline RSBC & 3 & 200003 & 0,000015 & 5870 & 0,000511 \\
\hline IDI & 29 & 1589 & 0,018256 & 42 & 0,690476 \\
\hline SEMSA & 16 & 316 & 0,050603 & 39 & 0,410256 \\
\hline AATM & 13 & 182 & 0,071588 & 10 & 1,300000 \\
\hline ICO & 109 & 3500 & 0,031143 & 80 & 1,362500 \\
\hline SSRCTBT & 13 & 1407 & 0,009237 & 18 & 0,722222 \\
\hline SCS & 225 & 603379 & 0,000373 & 574 & 0,391986 \\
\hline ICS & 187 & 210480 & 0,000888 & 8173 & 0,022880 \\
\hline IES & 8 & 472 & 0,016950 & 17 & 0,470558 \\
\hline CSUB & 103 & 23608 & 0,004363 & 698 & 0,147564 \\
\hline HUGTiP & 105 & 13024 & 0,008062 & 241 & 0,435685 \\
\hline HC & 361 & 28752 & 0,008908 & 757 & 0,476882 \\
\hline HSJD & 134 & 7788 & 0,017207 & 224 & 0,598214 \\
\hline HSCSP & 113 & 21651 & 0,005219 & 525 & 0,215238 \\
\hline CSUVH & 103 & 45192 & 0,002279 & 1335 & 0,077154 \\
\hline FP & 106 & 4500 & 0,023556 & 70 & 1,514286 \\
\hline$*$ Presupuesto & ecoómico expresado en millones de pesetas. & & \\
\hline & & & & & \\
\hline
\end{tabular}

Fuente: Encuesta, preguntas 14, 4 y 1. Número de respuestas: 69.

En esta tabla se observa que el mayor número de otras publicaciones tiene el hospital Clínic, el mayor presupuesto el SCS y el mayor número de personal de nivel superior el ICS. Con relación al índice otras publicaciones-presupuesto la AATM tiene el mayor índice y con relación al índice otras publicacionespersonal de nivel superior la Fundació Puigvert tiene el mayor índice. 
TABLA 7.6. Estadístico de las variables de todos los actores.

\begin{tabular}{|l|c|c|}
\hline Variable & Media & Desviación típica \\
\hline Actividad científica & 282,26 & 348,02 \\
\hline Otras publicaciones & 72,48 & 91,19 \\
\hline Personal de nivel superior & 1321,74 & 2052,38 \\
\hline Presupuesto económico & $6,79 \mathrm{E}+10$ & $1,31 \mathrm{E}+11$ \\
\hline
\end{tabular}

Fuente: Elaboración propia a partir de la Encuesta.

En esta tabla se observa que la desviación típica es mayor que la media para todas las variables significando que hay una fuerte dispersión entre el mínimo y el máximo estadístico de cada variable y que existe una acentuada heterogeneidad entre los grupos de actores estudiados.

TABLA 7.7. Análisis de Regresión Lineal de actividad científica.

\begin{tabular}{|l|c|c|c|c|}
\hline $\begin{array}{l}\text { Variables } \\
\text { predictoras }\end{array}$ & $\begin{array}{c}\mathrm{R} \\
\text { Correlación de } \\
\text { Pearson }\end{array}$ & $\begin{array}{c}\mathrm{R}^{2} \\
\text { Coeficiente de } \\
\text { determinación }\end{array}$ & $\mathrm{R}^{2}$ corregida & $\begin{array}{c}\text { Significación del } \\
\text { cambio en } \mathrm{F}\end{array}$ \\
\hline $\begin{array}{l}\text { Personal de } \\
\text { nivel superior }\end{array}$ & 0,329 & 0,108 & 0,065 & 0,126 \\
\hline $\begin{array}{l}\text { Presupuesto } \\
\text { económico }\end{array}$ & 0,310 & 0,096 & 0,053 & 0,150 \\
\hline
\end{tabular}

Fuente: Elaboración propia a partir de la Encuesta.

En esta tabla se observa que para el modelo propuesto el coeficiente 0,108 indica que por cada unidad de cambio en personal de nivel superior se produce un cambio de 0,108 unidades $[10,8 \%]$ en la actividad científica con la significación del $0,126[87,4 \%]$ y el coeficiente 0,096 indica que por cada unidad de cambio en el presupuesto económico se produce un cambio de 0,096 unidades $[9,6 \%]$ en la actividad científica con la significación del 0,150 [85,0\%].

Como se puede comprobar los resultados estadísticos muestran unos valores de $\mathrm{R}^{2}$ corregida muy próximos a cero por lo que se puede concluir que existe poca relación del presupuesto económico global y del personal de nivel superior de los actores con la actividad científica y también que la significación del modelo alrededor del $85 \%$ es baja.

En otras palabras, el presupuesto económico global y el personal de nivel superior están destinados a todas las actividades que éste desarrolla en el 
cumplimiento de sus funciones dentro del sistema, por lo que no se puede determinar que exista una relación directa entre actividad científica-personal de nivel superior y actividad científica-presupuesto económico. Interviniendo otros factores explicativos en la producción de actividad científica que presentan los diversos actores.

TABLA 7.8. Análisis de Regresión Lineal de otras publicaciones.

\begin{tabular}{|l|c|c|c|c|}
\hline $\begin{array}{l}\text { Variables } \\
\text { predictoras }\end{array}$ & $\begin{array}{c}\mathrm{R} \\
\text { Correlación de } \\
\text { Pearson }\end{array}$ & $\begin{array}{c}\mathrm{R}^{2} \\
\text { Coeficiente de } \\
\text { determinación }\end{array}$ & $\mathrm{R}^{2}$ corregida & $\begin{array}{c}\text { Significación del } \\
\text { cambio en } \mathrm{F}\end{array}$ \\
\hline $\begin{array}{l}\text { Personal de } \\
\text { nivel superior }\end{array}$ & 0,036 & 0,01 & $-0,046$ & 0,871 \\
\hline $\begin{array}{l}\text { Presupuesto } \\
\text { económico }\end{array}$ & 0,338 & 0,114 & 0,072 & 0,115 \\
\hline
\end{tabular}

Fuente: Elaboración propia a partir de la Encuesta.

En esta tabla se observa que para el modelo propuesto el coeficiente 0,01 indica que por cada unidad de cambio en personal de nivel superior se produce un cambio de 0,01 unidades $[1,0 \%$ de otras publicaciones con una muy poca significación del $0,871[12,9 \%$ y el coeficiente 0,114 indica que por cada unidad de presupuesto económico se produce un cambio de 0,114 unidades $[11,4 \%]$ en otras publicaciones con la significación del 0,115 [88,5\%].

Como se puede comprobar los resultados estadísticos muestran unos valores de $\mathrm{R}^{2}$ muy próximos a cero por lo que se puede concluir que existe poca relación del presupuesto económico global y del personal de nivel superior de los actores con otras publicaciones. El valor de la $\mathrm{R}^{2}$ corregida negativo indica una relación inversa entre otras publicaciones-personal de nivel superior, por lo tanto la no-validez de la hipótesis.

En otras palabras, el hecho de que el actor tenga una mayor plantilla de personal de nivel superior no hace prever que tenga un mayor número de otras publicaciones.

\subsubsection{INTERPRETACIÓN DE LOS RESULTADOS OBTENIDOS}

Los resultados de las diferentes tablas presentan una tendencia común no confirmando el grupo de hipótesis de partida. El presupuesto económico global no se relaciona de forma significativa con el número de actividad científica y otras publicaciones que producen los actores del SI—SSPC. También el número 
de personal de nivel superior no se relaciona de forma significativa con el número de actividad científica y otras publicaciones. Las diferencias entre los resultados son significativas, la desviación típica es mayor que la media para todas las variables lo que significa que existe una fuerte dispersión entre el mínimo y el máximo estadístico existiendo una gran heterogeneidad entre todos los actores. La tabla 7.9. muestra el resumen de los resultados de esta fase.

TABLA 7.9. Resultados del estudio de la Fase 1.

\begin{tabular}{|c|c|c|c|c|c|c|c|}
\hline Variable Actor & SCS & ICS & CSUVH & $\mathrm{HC}$ & AATM & IDI & FP \\
\hline $\begin{array}{l}>\text { presupuesto } \\
\text { económico }\end{array}$ & $\mathbf{X}$ & & & & & & \\
\hline > plantilla PNS & & $\mathbf{X}$ & & & & & \\
\hline $\begin{array}{c}>n^{\circ} \text { actividad } \\
\text { científica }\end{array}$ & & & $\bar{x}$ & & & & \\
\hline $\begin{array}{l}>n^{0} \text { otras } \\
\text { publicaciones }\end{array}$ & & & & $\mathbf{X}$ & & & \\
\hline $\begin{array}{l}>\text { AC/ presupuesto } \\
\text { económico }\end{array}$ & & & & & $\mathbf{X}$ & & \\
\hline $\begin{array}{l}>\text { AC/ plantilla } \\
\text { PNS }\end{array}$ & & & & & & $\bar{x}$ & \\
\hline$>$ OP / presupuesto & & & & & $\bar{x}$ & & \\
\hline $\begin{array}{l}>\text { OP / plantilla } \\
\text { PNS }\end{array}$ & & & & & & & $\bar{x}$ \\
\hline
\end{tabular}

Fuente: Elaboración propia a partir de la Encuesta.

En primer lugar se ha constatado como la AATM que tiene el menor presupuesto económico y la menor plantilla de personal de nivel superior, que podría constituir barreras en su aportación científica al SI—SSPC, se encuentra con el mayor índice de actividad científica — presupuesto económicoyel mayoríndice deotras publicacionespresupuesto económico en comparación con los demás actores del sistema. Por lo tanto, la AATM es el actor que con relación al presupuesto económico que dispone es el que mayor número actividad científica y otras publicaciones produce.

En segundo lugar, se ha constatado que la CSUVH y el Hospital Clínic son los dos hospitales de alta tecnología que más aportación de actividad científica y otras publicaciones hacen al sistema. El IDI tiene el mayor índice actividad científica-personal de nivel superior y la Fundació Puigvert tiene el mayor índice otras publicaciones-personal de nivel superior. 
En conclusión, el objetivo de este apartado ha sido comprobar individualmente el comportamiento diferenciado de los actores dentro del SI-SSPC. Este comportamiento es consecuencia de los condicionantes y de la política de la propia existencia del sistema. La manera en que se ha mostrado este comportamiento diferenciado ha sido a través de la aplicación de los dos grupos de hipótesis en los dos ámbitos de aportación de los actores al sistema.

\subsection{FASE 2. ANÁLISIS COMPARATIVO ENTRE EL ACTOR REGIONES SANITARIAS DEL SERVEI CATALÀ DE LA SALUT}

Las hipótesis a contrastar en esta fase son las siguientes:

2.1.Los resultados de aportación de la actividad científica de las Regiones Sanitarias serán significativamente diferentes.

2.2. Un mayor número de personal de nivel superior fomenta la actividad científica.

2.3. Un mayor presupuesto proporciona un resultado de la actividad científica significativamente superior.

TABLA 7.10. Resumen de las variables analizadas en esta fase.

\begin{tabular}{|l|l||}
\hline Variable & Descripción de la variable \\
\hline \hline Presupuesto económico & $\begin{array}{l}\text { Se obtuvo a partir del presupuesto anual asignado } \\
\text { a los actores del estudio. }\end{array}$ \\
\hline \hline Personal de nivel superior & $\begin{array}{l}\text { Se obtuvo a partir del total de profesionales de } \\
\text { nivel superior de la plantilla de cada uno de los } \\
\text { actores. }\end{array}$ \\
\hline \hline Actividad científica & $\begin{array}{l}\text { Se obtuvo a partir de la suma de la actividad } \\
\text { científica divulgadora, participación u organización } \\
\text { de congresos nacionales e internacionales, } \\
\text { simposios, cursos, jornadas, conferencias, actos, } \\
\text { seminarios y otros [no se incluye en esta variable } \\
\text { las publicaciones SCI u otras publicaciones que } \\
\text { producen los actores del sistema y que son } \\
\text { analizadas por separado]. }\end{array}$ \\
\hline \hline $\begin{array}{l}\text { Publicaciones de libros, } \\
\text { capítulos de libros y demás }\end{array}$ & $\begin{array}{l}\text { Se obtuvo a partir del número de publicaciones } \\
\text { efectuadas por los actores del estudio [se incluye } \\
\text { en esta variable todas las demás publicaciones } \\
\text { publicaciones - otras } \\
\text { publicaciones- } \\
\text { producidas por los actores del SI-SSPC } \\
\text { excluyendo las publicaciones SCI]. }\end{array}$ \\
\hline \hline
\end{tabular}

Fuente: Elaboración propia. 


\subsubsection{RESULTADO Y DESCRIPCIÓN DE LAS TABLAS}

Resultados de la aportación de actividad científica y de número de otras publicaciones de las Regiones Sanitarias.

TABLA 7.11. Resultados de la actividad científica y número de otras publicaciones de cada región sanitaria.

\begin{tabular}{|l|c|c|c|c|}
\hline Región sanitaria & $\begin{array}{c}\text { No actividad } \\
\text { científica }\end{array}$ & $\begin{array}{c}\text { \% sobre el } \\
\text { total }\end{array}$ & $\begin{array}{c}\text { No de otras } \\
\text { publicaciones }\end{array}$ & \% sobre el total \\
\hline RSL & 23 & 13,5 & 4 & 9,5 \\
\hline RST & 8 & 4,7 & 4 & 9,5 \\
\hline RSTO & 25 & 14,7 & 7 & 16,7 \\
\hline RSG & 18 & 10,6 & 9 & 21,4 \\
\hline RSCP & 17 & 10,0 & 8 & 19,0 \\
\hline RSBNM & 54 & 31,8 & 5 & 11,9 \\
\hline RSC & 8 & 4,7 & 2 & 4,8 \\
\hline RSBC & 17 & 10,0 & 3 & 7,1 \\
\hline TOTAL & 170 & 100,0 & 42 & 100,0 \\
\hline
\end{tabular}

Fuente: Encuesta, preguntas 6 y 14. Número de respuestas: 16.

Del total de actividad científica de las regiones sanitarias se destaca la RSBNM con el 31,8\% de la actividad científica realizada por todas las regiones sanitarias, seguida por la RSTO con el 14,7\%. Las RST y RSC fueron las que realizaron una menor aportación de actividad científica el 4,7\% del total respectivamente.

Del total de publicaciones se destaca la RSG con el 21,4\% y la RSCP con el $19,0 \%$. Las RSBC y RSC fueran las que menos publicaron con el 7,1\% y el 4,8\% de las publicaciones respectivamente. 
TABLA 7.12. Resultados del presupuesto económico destinado a cada región sanitaria.

\begin{tabular}{|l|c|c|c|c|}
\hline Región sanitaria & $\begin{array}{c}\text { Presupuesto } \\
\text { económico }\end{array}$ & $\begin{array}{c}\text { \% sobre el } \\
\text { total }\end{array}$ & $\begin{array}{c}\text { Personal nivel } \\
\text { superior }\end{array}$ & \% sobre el total \\
\hline RSL & 28.106 .057 .000 & 4,8 & 884 & 5,0 \\
\hline RST & 39.727 .529 .000 & 6,8 & 1049 & 6,0 \\
\hline RSTO & 11.531 .624 .000 & 2,0 & 345 & 2,0 \\
\hline RSG & 43.186 .085 .000 & 7,4 & 1258 & 7,1 \\
\hline RSCP & 103.483 .310 .000 & 17,7 & 2982 & 16,9 \\
\hline RSBNM & 57.364 .926 .000 & 9,8 & 1609 & 9,1 \\
\hline RSC & 101.558 .600 .000 & 17,4 & 3600 & 20,5 \\
\hline RSBC & 200.003 .480 .000 & 34,2 & 5870 & 33,4 \\
\hline TOTAL & 584.961 .611 .000 & 100,0 & 17597 & 100,0 \\
\hline
\end{tabular}

Fuente: Encuesta, preguntas 4 y 1. Número de respuestas: 16.

Del total de personal de nivel superior de las regiones sanitarias la RSBC tiene la mayor plantilla con 33,4\% del personal, seguida por la RSC con el 20,5\% del personal. Las RSL y RSTO tienen las menores plantillas de personal de nivel superior con el 5,0\% y el 2,0\% respectivamente. Del total del presupuesto económico la RSBC recibe el 34,2\% seguida de la RSCP con el 17,7\% del presupuesto económico. Las RSL y RSTO reciben el menor presupuesto económico con el 4,8\% y el 2,0\% respectivamente.

TABLA 7.13. Otros datos de las regiones sanitarias.

\begin{tabular}{|l|c|c|c|c|c|}
\hline $\begin{array}{l}\text { Región } \\
\text { sanitaria }\end{array}$ & $\begin{array}{c}\text { Renta } \\
\text { percápita }\end{array}$ & $\begin{array}{c}\text { Área } \\
\text { geográfica }\end{array}$ & Población & $\begin{array}{c}\text { Hospitales } \\
1-2-3^{*}\end{array}$ & $\begin{array}{c}\text { Hospitales } \\
4 *\end{array}$ \\
\hline RSL & $12,7 \%$ & $35,9 \%$ & $5,0 \%$ & $11,5 \%$ & $0,0 \%$ \\
\hline RST & $11,8 \%$ & $11,5 \%$ & $6,1 \%$ & $9,8 \%$ & $0,0 \%$ \\
\hline RSTO & $13,1 \%$ & $7,3 \%$ & $2,0 \%$ & $1,6 \%$ & $0,0 \%$ \\
\hline RSG & $12,8 \%$ & $16,5 \%$ & $7,4 \%$ & $13,1 \%$ & $0,0 \%$ \\
\hline RSCP & $11,8 \%$ & $6,2 \%$ & $16,5 \%$ & $13,1 \%$ & $30,0 \%$ \\
\hline RSBNM & $11,8 \%$ & $2,6 \%$ & $20,3 \%$ & $8,2 \%$ & $10,0 \%$ \\
\hline RSC & $11,8 \%$ & $19,7 \%$ & $18,4 \%$ & $23,0 \%$ & $0,0 \%$ \\
\hline RSBC & $14,5 \%$ & $0,3 \%$ & $24,3 \%$ & $19,7 \%$ & $60,0 \%$ \\
\hline * Clasificación de los hosptales de la XHUP, Grupos $1,2,3,4$. \\
\hline
\end{tabular}

Fuente: Elaboración propia a partir de la bibliografía seleccionada. 
TABLA 7.14. Resultados de la actividad científica por presupuesto y personal de nivel superior.

\begin{tabular}{|l|c|c|c|c|c|}
\hline Región sanitaria & $\begin{array}{c}\text { Actividad } \\
\text { científica }\end{array}$ & $\begin{array}{c}\text { Presupuesto } \\
\text { económico* }\end{array}$ & $\begin{array}{c}\text { AC/ } \\
\text { presupuesto }\end{array}$ & $\begin{array}{c}\text { Personal de } \\
\text { nivel superior }\end{array}$ & $\begin{array}{c}\text { AC/ personal de } \\
\text { nivel superior }\end{array}$ \\
\hline RSL & 23 & 28106 & 0,000818 & 884 & 0,026018 \\
\hline RST & 8 & 39728 & 0,000201 & 1049 & 0,007626 \\
\hline RSTO & 25 & 11532 & 0,002168 & 345 & 0,072464 \\
\hline RSG & 18 & 43186 & 0,000417 & 1258 & 0,014308 \\
\hline RSCP & 17 & 103483 & 0,000164 & 2982 & 0,005701 \\
\hline RSBNM & 54 & 57365 & 0,000941 & 1609 & 0,033561 \\
\hline RSC & 8 & 101559 & 0,000079 & 3600 & 0,002222 \\
\hline RSBC & 17 & 200003 & 0,000085 & 5870 & 0,002896 \\
\hline$*$ Presupuesto económico expresado en millones de pesetas. \\
\hline
\end{tabular}

Fuente: Encuesta, preguntas 6, 4 y 1. Número de respuestas: 24.

En esta tabla se observa que el mayor número de actividad científica lo tiene RSBNM, el mayor presupuesto la RSBC y el mayor número de personal de nivel superior también la RSBC. Con relación al índice actividad científica一presupuesto la RSTO tiene el mayor índice y también con relación al índice actividad científica-personal de nivel superior la RSTO tiene el mayor índice.

TABLA 7.15. Resultados de otras publicaciones por presupuesto y personal de nivel superior.

\begin{tabular}{|l|c|c|c|c|c|}
\hline Región sanitaria & $\begin{array}{c}\text { Otras } \\
\text { publicaciones }\end{array}$ & $\begin{array}{c}\text { Presupuesto } \\
\text { económico* }\end{array}$ & $\begin{array}{c}\text { OP/ } \\
\text { presupuesto }\end{array}$ & $\begin{array}{c}\text { Personal de } \\
\text { nivel superior }\end{array}$ & $\begin{array}{c}\text { OP / personal } \\
\text { de nivel superior }\end{array}$ \\
\hline RSL & 4 & 28106 & 0,000142 & 884 & 0,004525 \\
\hline RST & 4 & 39728 & 0,000101 & 1049 & 0,003813 \\
\hline RSTO & 7 & 11532 & 0,000607 & 345 & 0,020290 \\
\hline RSG & 9 & 43186 & 0,000208 & 1258 & 0,007154 \\
\hline RSCP & 8 & 103483 & 0,000077 & 2982 & 0,002683 \\
\hline RSBNM & 5 & 57365 & 0,000087 & 1609 & 0,003108 \\
\hline RSC & 2 & 101559 & 0,000020 & 3600 & 0,000556 \\
\hline RSBC & 3 & 200003 & 0,000015 & 5870 & 0,000511 \\
\hline * Presupuesto económico expresado en millones de pesetas. \\
\hline
\end{tabular}

Fuente: Encuesta, preguntas 14, 4 y 1. Número de respuestas: 24.

En esta tabla se observa que el mayor número de otras publicaciones lo tiene RSG, el mayor presupuesto la RSBC y el mayor número de personal de nivel 
superior también la RSBC. Con relación al índice otras publicacionespresupuesto la RSTO tiene el mayor índice y también con relación al índice otras publicaciones_-personal de nivel superior la RSTO tiene el mayor índice.

TABLA 7.16. Comparación de los estadísticos de las variables de las regiones sanitarias con todos los actores.

\begin{tabular}{|l|c|c|c|c|}
\hline Variable & $\begin{array}{c}\text { Media de las } \\
\text { Regiones } \\
\text { Sanitarias }\end{array}$ & $\begin{array}{c}\text { Media } \\
\text { de todos los } \\
\text { actores }\end{array}$ & $\begin{array}{c}\text { Desviación } \\
\text { típica de las } \\
\text { Regiones } \\
\text { Sanitarias }\end{array}$ & $\begin{array}{c}\text { Desviación } \\
\text { típica de todos los } \\
\text { actores }\end{array}$ \\
\hline $\begin{array}{l}\text { Actividad } \\
\text { científica }\end{array}$ & 21,25 & 282,26 & 14,58 & 348,02 \\
\hline $\begin{array}{l}\text { Otras } \\
\text { publica ciones }\end{array}$ & 5,25 & 72,48 & 2,49 & 91,19 \\
\hline $\begin{array}{l}\text { Personal de } \\
\text { nivel superior }\end{array}$ & 2199,63 & 1321,74 & 1842,93 & 2052,38 \\
\hline $\begin{array}{l}\text { Presupuesto } \\
\text { económico }\end{array}$ & $7,31 \mathrm{E}+10$ & $6,79 \mathrm{E}+10$ & $6,08 \mathrm{E}+10$ & $1,31 \mathrm{E}+11$ \\
\hline
\end{tabular}

Fuente: Elaboración propia a partir de la Encuesta.

En esta tabla se observa la media y desviación típica de las variables de las Regiones Sanitarias y para todas las variables, excepción de otras publicaciones, la desviación típica es menor que la media significando que existe una mayor homogeneidad entre las Regiones Sanitarias. Con relación a la comparación de las Regiones Sanitarias con todos los actores se observa que la media y desviación típica de las Regiones Sanitarias es menor significando que para todas las variables estudiadas las Regiones Sanitarias tienen una baja aportación al SI—SSPC.

TABLA 7.17. Análisis de Regresión Lineal de actividad científica.

\begin{tabular}{|l|c|c|c|c|}
\hline $\begin{array}{l}\text { Variables } \\
\text { predictoras }\end{array}$ & $\begin{array}{c}\mathrm{R} \\
\text { Correlación de } \\
\text { Pearson }\end{array}$ & $\begin{array}{c}\mathrm{R}^{2} \\
\text { Coeficiente de } \\
\text { determinación }\end{array}$ & $\mathrm{R}^{2}$ corregida & $\begin{array}{c}\text { Significación del } \\
\text { cambio en } \mathrm{F}\end{array}$ \\
\hline $\begin{array}{l}\text { Personal de } \\
\text { nivel superior }\end{array}$ & 0,254 & 0,065 & $-0,91$ & 0,544 \\
\hline $\begin{array}{l}\text { Presupuesto } \\
\text { económico }\end{array}$ & 0,214 & 0,046 & $-0,113$ & 0,610 \\
\hline
\end{tabular}

Fuente: Elaboración propia a partir de la Encuesta. 
En esta tabla se observa que para el modelo propuesto el coeficiente 0,065 indica que por cada unidad de cambio en personal de nivel superior se produce un cambio de 0,065 unidades [6,5\%] en la actividad científica con la significación del $0,544[45,6 \%]$ y el coeficiente 0,046 indica que por cada unidad de cambio en el presupuesto económico se produce un cambio de 0,046 unidades $[4,6 \%]$ en otras publicaciones con la significación del 0,610 [39,0\%].

Como se puede comprobar los resultados estadísticos muestran unos valores de $\mathrm{R}^{2}$ muy próximos a cero por lo que se puede concluir que existe poca relación del presupuesto económico global y del personal de nivel superior de los actores con la actividad científica de las regiones sanitarias, por lo que no se puede determinar que exista una relación directa entre actividad científica—personal de nivel superior y actividad científica—presupuesto económico. Interviniendo otros factores explicativos en la producción de actividad científica que presentan los diversos actores.

El valor de la $\mathrm{R}^{2}$ corregida negativo para los dos casos indica una relación inversa entre actividad científica-personal de nivel superior y actividad científica-presupuesto económico, por lo tanto la no—validez de las hipótesis. En otras palabras, el hecho de que las regiones sanitarias tengan una mayor plantilla de personal de nivel superior y un mayor presupuesto económico no hace prever que desarrollen un mayor número de actividad científica.

TABLA 7.18. Análisis de Regresión Lineal de otras publicaciones.

\begin{tabular}{|l|c|c|c|c|}
\hline $\begin{array}{l}\text { Variables } \\
\text { predictoras }\end{array}$ & $\begin{array}{c}\mathrm{R} \\
\text { Correlación de } \\
\text { Pearson }\end{array}$ & $\begin{array}{c}\mathrm{R}^{2} \\
\text { Coeficiente de } \\
\text { determinación }\end{array}$ & $\mathrm{R}^{2}$ corregida & $\begin{array}{c}\text { Significación del } \\
\text { cambio en } \mathrm{F}\end{array}$ \\
\hline $\begin{array}{l}\text { Personal de } \\
\text { nivel superior }\end{array}$ & 0,442 & 0,195 & 0,061 & 0,273 \\
\hline $\begin{array}{l}\text { Presupuesto } \\
\text { económico }\end{array}$ & 0,389 & 0,151 & 0,009 & 0,341 \\
\hline
\end{tabular}

Fuente: Elaboración propia a partir de la Encuesta.

En esta tabla se observa que para el modelo propuesto el coeficiente 0,195 indica que por cada unidad de cambio en personal de nivel superior se produce un cambio de 0,195 [19,5\%] en otras publicaciones con la significación de 0,273 $[72,7 \%]$ y el coeficiente 0,151 indica que por cada unidad de cambio en el presupuesto económico se produce un cambio de 0,151 unidades $[15,1 \%]$ en otras publicaciones con la significación del 0,341 [65,9\%]. 
Como se puede comprobar los resultados estadísticos muestran unos valores de $\mathrm{R}^{2}$ muy próximos a cero por lo que se puede concluir que existe poca relación del presupuesto económico global y del personal de nivel superior de los actores con otras publicaciones, por lo que no se puede determinar que exista una relación directa entre otras publicaciones-personal de nivel superior y otras publicaciones - presupuesto económico. Interviniendo otros factores explicativos en la producción de otras publicaciones que presentan los diversos actores.

En otras palabras, el hecho de que el actor tenga una mayor plantilla de personal de nivel superior y un mayor presupuesto económico no hace prever que tenga un mayor número de otras publicaciones.

\subsubsection{INTERPRETACIÓN DE LOS RESULTADOS OBTENIDOS}

El objetivo de la contrastación de este segundo grupo de hipótesis ha sido analizar el comportamiento diferenciado de las regiones sanitarias del SCS dentro del SI-SSPC.

Por lo tanto, más que validar o no las hipótesis se ha tratado de observar como ha sido el comportamiento de las regiones sanitarias. La tabla 7.19 muestra el resumen de los resultados de esta fase.

TABLA 7.19. Resultados del estudio de la Fase 2.

\begin{tabular}{|c|c|c|c|c|}
\hline Región sanitaria & RSBC & RSTO & RSBNM & RSG \\
\hline $\begin{array}{c}\text { Variable presupuesto } \\
\text { económico }\end{array}$ & $\mathbf{X}$ & & & \\
\hline $\begin{array}{c}>\text { personal de } \\
\text { nivel superior }\end{array}$ & $\mathbf{X}$ & & $\mathbf{X}$ & \\
\hline $\begin{array}{c}>\mathrm{n}^{\circ} \text { actividad } \\
\text { científica }\end{array}$ & & $\mathbf{X}$ & & $\mathbf{X}$ \\
\hline $\begin{array}{c}>\mathrm{n}^{\circ} \text { otras } \\
\text { publicaciones }\end{array}$ & & $\mathbf{X}$ & & \\
\hline $\begin{array}{c}>\text { AC/ presupuesto } \\
\text { económico }\end{array}$ & & $\mathbf{X}$ & & \\
\hline $\begin{array}{c}>\text { AC/ personal de } \\
\text { nivel superior }\end{array}$ & & $\mathbf{X}$ & & \\
\hline $\begin{array}{c}>\text { OP / } \\
\text { presupuesto }\end{array}$ & & & & \\
\hline $\begin{array}{c}>\text { OP / personal de } \\
\text { nivel superior }\end{array}$ & & & & \\
\hline
\end{tabular}

Fuente: Elaboración propia a partir de la Encuesta. 
En primer lugar se ha constatado como la RSTO que tiene el menor presupuesto económico y la menor plantilla de personal de nivel superior, que podría constituir barreras en su aportación científica al SI—SSPC, se encuentra con el mayor índice de actividad científica-presupuesto económico y el mayor índice de otras publicaciones-presupuesto económico en comparación con las demás regiones sanitarias. Por lo tanto, la RSTO es la región sanitaria que con relación al presupuesto económico que dispone es la que mayor actividad científica y otras publicaciones produce.

En segundo lugar, se ha constatado que la RSBNM es la que más aportación de actividad científica hace al sistema y la RSG es la que más aporta al sistema otras publicaciones. La RSTO tiene el mayor índice los dos grupos de hipótesis 2.2 y 2.3 y para las dos variables estudiadas.

Los resultados obtenidos confirman la primera hipótesis 2.1 y como en la Fase 1 los resultados de todas las tablas presentan una tendencia común no confirmando las dos hipótesis siguientes 2.2 y 2.3. El presupuesto económico global no se relaciona de forma significativa con el número de actividad científica y otras publicaciones que producen las regiones sanitarias del SI-SSPC. También el número de personal de nivel superior no se relaciona de forma significativa con el número de actividad científica y otras publicaciones. Las diferencias entre los resultados son menos significativas que en la fase anterior, la desviación típica, con excepción del presupuesto económico, es menor que la media para todas las variables lo que significa que existe una dispersión pequeña entre el mínimo y el máximo estadístico existiendo una gran homogeneidad en la aportación de las regiones sanitarias al sistema en comparación al conjunto total de los actores.

En tercer lugar, se ha constatado con la comparación de las medias de la actividad científica $[21,25]$ y de otras publicaciones [5,25] de las regiones sanitarias con la media de todos los actores $[282,26]$ y $[72,48]$, respectivamente, que las regiones sanitarias no están ubicadas en el polo científico o tecnológico del SI-SSPC. En conclusión, el objetivo de este apartado ha sido comprobar individualmente el comportamiento diferenciado de las regiones sanitarias dentro del SI-SSPC. 


\subsection{FASE 3. ANÁLISIS COMPARATIVO ENTRE LAS EMPRESAS PÚBLICAS DEL SERVEI CATALÀ DE LA SALUT}

Las hipótesis a contrastar en esta fase son las siguientes:

3.1. El valor del presupuesto económico se relaciona significativamente con los resultados de la actividad científica y con el número de otras publicaciones de las empresas.

3.2. El número de personal de nivel superior se relaciona significativamente con los resultados de la actividad científica y con el número de otras publicaciones de las empresas.

TABLA 7.20. Resumen de las variables analizadas en esta fase.

\begin{tabular}{||l|l||}
\hline Variable & Descripción de la variable \\
\hline \hline Presupuesto económico & $\begin{array}{l}\text { Se obtuvo a partir del presupuesto anual asignado } \\
\text { a los actores del estudio. }\end{array}$ \\
\hline \hline Personal de nivel superior & $\begin{array}{l}\text { Se obtuvo a partir del total de profesionales de } \\
\text { nivel superior de la plantilla de cada uno de los } \\
\text { actores. }\end{array}$ \\
\hline \hline Actividad científica & $\begin{array}{l}\text { Se obtuvo a partir de la suma de la actividad } \\
\text { científica divulgadora, participación u organización } \\
\text { de congresos nacionales e internacionales, } \\
\text { simposios, cursos, jornadas, conferencias, actos, } \\
\text { seminarios y otros [no se incluye en esta variable } \\
\text { las publicaciones SCI u otras publicaciones que } \\
\text { producen los actores del sistema y que son } \\
\text { analizadas por separado]. }\end{array}$ \\
\hline \hline $\begin{array}{l}\text { Publicaciones de libros, } \\
\text { capítulos de libros y demás }\end{array}$ & $\begin{array}{l}\text { Se obtuvo a partir del número de publicaciones } \\
\text { efectuadas por los actores del estudio [se incluye } \\
\text { en esta variable todas las demás publicaciones } \\
\text { producidas por los actores del SI-SSPC } \\
\text { publicaciones - otras } \\
\text { excluyendo las publicaciones SCI]. }\end{array}$ \\
\hline \hline
\end{tabular}

Fuente: Elaboración propia.

\subsubsection{RESULTADO Y DESCRIPCIÓN DE LAS TABLAS}

Resultados del presupuesto económico y del personal de nivel superior de las empresas públicas. 
TABLA 7.21. Resultados del presupuesto económico y del número de personal de nivel superior de las empresas públicas.

\begin{tabular}{|l|c|c|c|c|}
\hline $\begin{array}{l}\text { Empresa } \\
\text { pública }\end{array}$ & $\begin{array}{c}\text { Presupuesto } \\
\text { económico }\end{array}$ & $\%$ sobre el total & $\begin{array}{c}\text { Personal de } \\
\text { nivel superior }\end{array}$ & $\%$ sobre el total \\
\hline IDI & 1.588 .521 .975 & 45,5 & 42 & 38,5 \\
\hline SEMSA & 316.183 .755 & 9,1 & 39 & 35,8 \\
\hline AATM & 181.595 .294 & 5,2 & 10 & 9,2 \\
\hline SSRCTBT & 1.407 .386 .332 & 40,3 & 18 & 16,5 \\
\hline TOTAL & 3.493 .687 .356 & 100,0 & 109 & 100,0 \\
\hline
\end{tabular}

Fuente: Encuesta, preguntas 4 y 1. Número de respuestas: 8.

Del total del presupuesto de las empresas públicas del SCS estudiadas se destaca el IDI con el 42,7\% seguido del SSRCTBT con el 42,3\%. Del total de personal de nivel superior de las empresas públicas se destaca también el IDI con el 38,5\% seguido por SEMSA con el 35,8\%.

TABLA 7.22. Resultados de la actividad científica y del número de otras publicaciones de las empresas públicas.

\begin{tabular}{|l|c|c|c|c|}
\hline $\begin{array}{l}\text { Empresa } \\
\text { pública }\end{array}$ & $\begin{array}{l}\text { Actividad } \\
\text { científica }\end{array}$ & $\%$ sobre el total & $\begin{array}{c}\text { Otras } \\
\text { publicaciones }\end{array}$ & $\%$ sobre el total \\
\hline IDI & 951 & 80,6 & 29 & 40,8 \\
\hline SEMSA & 58 & 4,9 & 16 & 22,5 \\
\hline AATM & 114 & 9,7 & 13 & 18,3 \\
\hline SSRCTBT & 57 & 4,8 & 13 & 18,3 \\
\hline TOTAL & 1180 & 100,0 & 71 & 100,0 \\
\hline
\end{tabular}

Fuente: Encuesta, preguntas 6 y 14. Número de respuestas: 8 .

Del total de la actividad científica generada por las empresas públicas del SCS estudiadas se destaca el IDI con el 82,2\% seguido por la AATM con el 9,9\%. Del total de publicaciones generadas por las empresas públicas se destaca también el IDI con el 40,8\% seguido por el SEMSA con el 22,5\%. 
TABLA 7.23. Resultados de la actividad científica por presupuesto y personal de nivel superior.

\begin{tabular}{|c|c|c|c|c|c|}
\hline $\begin{array}{l}\text { Empresa } \\
\text { pública }\end{array}$ & $\begin{array}{l}\text { Actividad } \\
\text { científica }\end{array}$ & $\begin{array}{l}\text { Presupuesto } \\
\text { económico* }\end{array}$ & $\begin{array}{c}\mathrm{AC} / \\
\text { presupuesto }\end{array}$ & $\begin{array}{c}\text { Personal de } \\
\text { nivel superior }\end{array}$ & $\begin{array}{l}\text { AC / personal de } \\
\text { nivel superior }\end{array}$ \\
\hline IDI & 951 & 1589 & 0,598670 & 42 & 22,64286 \\
\hline SEMSA & 58 & 316 & 0,183438 & 39 & 1,487179 \\
\hline AATM & 114 & 182 & 0,627770 & 10 & 11,40000 \\
\hline SSRCTBT & 57 & 1407 & 0,040501 & 18 & 3,166767 \\
\hline
\end{tabular}

Fuente: Encuesta, preguntas 6, 4 y 1. Número de respuestas: 12.

En esta tabla se observa que el mayor número de actividad científica, el mayor presupuesto y el mayor número de personal de nivel superior tiene el IDI. Con relación al índice actividad científica-presupuesto es la AATM que tiene el mayor índice y con relación al índice actividad científica-personal de nivel superior el IDI tiene el mayor índice.

TABLA 7.24. Resultados de otras publicaciones por presupuesto y personal de nivel superior.

\begin{tabular}{|l|c|c|c|c|c|}
\hline $\begin{array}{l}\text { Empresa } \\
\text { pública }\end{array}$ & $\begin{array}{c}\text { Otras } \\
\text { publicaciones }\end{array}$ & $\begin{array}{c}\text { Presupuesto } \\
\text { económico* }\end{array}$ & $\begin{array}{c}\text { OP / } \\
\text { presupuesto }\end{array}$ & $\begin{array}{c}\text { Personal de } \\
\text { nivel superior }\end{array}$ & $\begin{array}{c}\text { OP / personal } \\
\text { de nivel superior }\end{array}$ \\
\hline IDI & 29 & 1589 & 0,018256 & 42 & 0,690476 \\
\hline SEMSA & 16 & 316 & 0,050603 & 39 & 0,410256 \\
\hline AATM & 13 & 182 & 0,071588 & 10 & 1,300000 \\
\hline SSRCTBT & 13 & 1407 & 0,009237 & 18 & 0,722222 \\
\hline * Presupuesto económico expresado en millones de pesetas.
\end{tabular}

Fuente: Encuesta, preguntas 14, 4 y 1. Número de respuestas: 12.

En esta tabla se observa que el mayor número de otras publicaciones, el mayor presupuesto y el mayor número de personal de nivel superior tiene el IDI. Con relación al índice otras publicaciones-presupuesto y al índice otras publicaciones-personal de nivel superior es la AATM que tiene el mayor índice en ambos casos. 
TABLA 7.25. Comparación de los estadísticos de las variables de las empresas públicas con todos los actores.

\begin{tabular}{|l|c|c|c|c|}
\hline Variable & $\begin{array}{c}\text { Media de las } \\
\text { empresas } \\
\text { públicas }\end{array}$ & $\begin{array}{c}\text { Media } \\
\text { de todos los } \\
\text { actores }\end{array}$ & $\begin{array}{c}\text { Desviación } \\
\text { típica de las } \\
\text { empresas } \\
\text { públicas }\end{array}$ & $\begin{array}{c}\text { Desviación } \\
\text { típica de todos los } \\
\text { actores }\end{array}$ \\
\hline $\begin{array}{l}\text { Actividad } \\
\text { científica }\end{array}$ & 295,0 & 282,26 & 438,14 & 348,02 \\
\hline $\begin{array}{l}\text { Otras } \\
\text { publicaciones }\end{array}$ & 17,75 & 72,48 & 2,49 & 91,19 \\
\hline $\begin{array}{l}\text { Personal de } \\
\text { nivel superior }\end{array}$ & 27,25 & 1321,74 & 7,63 & 2052,38 \\
\hline $\begin{array}{l}\text { Presupuesto } \\
\text { económico }\end{array}$ & $8,73 \mathrm{E}+10$ & $6,79 \mathrm{E}+10$ & $7,27 \mathrm{E}+10$ & $1,31 \mathrm{E}+11$ \\
\hline
\end{tabular}

Fuente: Elaboración propia a partir de la Encuesta.

En esta tabla se observa la media de las variables actividad científica y presupuesto económico de las empresas públicas son mayores que la media de todos los actores y en las variables otras publicaciones y personal de nivel superior la media de las empresas públicas son menores que la media de todos los actores. Con relación a la desviación típica para todas las variables, excepción de la actividad científica, la desviación típica de las empresas públicas es menor que la de todos los actores.

TABLA 7.26. Análisis de Regresión Lineal de actividad científica.

\begin{tabular}{|l|c|c|c|c|}
\hline $\begin{array}{l}\text { Variables } \\
\text { predictoras }\end{array}$ & $\begin{array}{c}\mathrm{R} \\
\text { Correlación de } \\
\text { Pearson }\end{array}$ & $\begin{array}{c}\mathrm{R}^{2} \\
\text { Coeficiente de } \\
\text { determinación }\end{array}$ & $\mathrm{R}^{2}$ corregida & $\begin{array}{c}\text { Significación del } \\
\text { cambio en } \mathrm{F}\end{array}$ \\
\hline $\begin{array}{l}\text { Personal de } \\
\text { nivel superior }\end{array}$ & 0,592 & 0,351 & 0,026 & 0,408 \\
\hline $\begin{array}{l}\text { Presupuesto } \\
\text { económico }\end{array}$ & 0,627 & 0,393 & 0,090 & 0,373 \\
\hline
\end{tabular}

Fuente: Elaboración propia a partir de la Encuesta.

En esta tabla se observa que para el modelo propuesto el coeficiente 0,351 indica que por cada unidad de cambio en personal de nivel superior se produce un cambio de 0,351 unidades $[35,1 \%]$ en la actividad científica con la significación del $0,408[59,2 \%]$ y el coeficiente 0,393 indica que por cada unidad de cambio en el presupuesto económico se produce un cambio de 0,393 unidades [39,3\%] en 
otras publicaciones con la significación del 0,373 [62,7\%]. Como se puede comprobar los resultados estadísticos muestran unos valores de $\mathrm{R}^{2}$ superiores a cero aunque no muestren una fuerte relación entre las variables sí que son significativamente superiores a los obtenidos en las fases anteriores del estudio. Podemos concluir, independientemente de la significación del cambio en F alrededor del 0,400 [60\%], que a una mayor plantilla de personal de nivel superior y a un mayor presupuesto económico hace prever una mayor producción de actividad científica en las empresas públicas.

TABLA 7.27. Análisis de Regresión Lineal de otras publicaciones.

\begin{tabular}{|l|c|c|c|c|}
\hline $\begin{array}{l}\text { Variables } \\
\text { predictoras }\end{array}$ & $\begin{array}{c}\mathrm{R} \\
\text { Correlación de } \\
\text { Pearson }\end{array}$ & $\begin{array}{c}\mathrm{R}^{2} \\
\text { Coeficiente de } \\
\text { determinación }\end{array}$ & $\mathrm{R}^{2}$ corregida & $\begin{array}{c}\text { Significación del } \\
\text { cambio en } \mathrm{F}\end{array}$ \\
\hline $\begin{array}{l}\text { Personal de } \\
\text { nivel superior }\end{array}$ & 0,755 & 0,570 & 0,355 & 0,245 \\
\hline $\begin{array}{l}\text { Presupuesto } \\
\text { económico }\end{array}$ & 0,587 & 0,344 & 0,017 & 0,413 \\
\hline
\end{tabular}

Fuente: Elaboración propia a partir de la Encuesta.

En esta tabla se observa que para el modelo propuesto el coeficiente 0,570 indica que por cada unidad de cambio en personal de nivel superior se produce un cambio de 0,570 [57,0\%] en otras publicaciones con la significación del $0,245[75,5 \%]$ y el coeficiente 0,344 indica que por cada unidad de cambio en el presupuesto económico se produce un cambio de 0,344 unidades $[34,4 \%]$ en otras publicaciones con la significación del 0,413 [58,7\%]. Como se puede comprobar los resultados estadísticos muestran unos valores de $\mathrm{R}^{2}$ superiores a cero aunque no muestren una fuerte relación entre las variables, nuevamente sí que son significativamente superiores a los obtenidos en las fases anteriores del estudio. Podemos concluir, que para las empresas públicas el hecho de tener una mayor plantilla de personal de nivel superior hace prever un mayor número de otras publicaciones.

\subsubsection{INTERPRETACIÓN DE LOS RESULTADOS OBTENIDOS}

Esta tercera fase de análisis ha tenido como objetivo analizar el comportamiento y la aportación que hacen las empresas públicas del SCS al SI-SSPC. 
Los resultados obtenidos confirman las hipótesis de partida. Por un lado el IDI tiene el mayor presupuesto económico y el mayor número de personal de nivel superior y a su vez produce el mayor número de actividad científica y de otras publicaciones. Por otro lado, como ya se había visto anteriormente es la AATM que tiene los mayores índices de actividad científicapresupuesto, otras publicaciones-presupuesto y otras publicacionespersonal de nivel superior. La tabla 7.28 muestra el resumen de los resultados de esta fase.

TABLA 7.28. Resultados del estudio de la Fase 3.

\begin{tabular}{|l|c|c|}
\hline \multicolumn{1}{|r|}{ Empresa pública } & IDI & AATM \\
\hline Variable & & \\
\hline$>$ presupuesto económico & $\mathbf{X}$ & \\
\hline$>\mathrm{n}^{0}$ actividad científica & $\mathbf{X}$ & \\
\hline$>\mathrm{n}^{0}$ otras publicaciones & $\mathbf{X}$ & $\mathbf{X}$ \\
\hline$>\mathrm{AC} /$ presupuesto económico & & \\
\hline$>\mathrm{AC} /$ personal de nivel superior & $\mathbf{X}$ & $\mathbf{X}$ \\
\hline$>$ OP / presupuesto & & $\mathbf{X}$ \\
\hline$>$ OP / personal de nivel superior & & \\
\hline
\end{tabular}

Fuente: Elaboración propia a partir de la Encuesta.

Respecto a la dispersión de los resultados, existe una gran heterogeneidad con relación a la actividad científica quedando en evidencia que el IDI produce más actividad científica en comparación con las otras empresas públicas que presentan una mayor homogeneidad entre sí.

En relación con otras publicaciones y personal de nivel superior la desviación típica es menor que la media para los dos casos existiendo una mayor homogeneidad para estas variables.

La comparación de la media de las variables de las empresas públicas con las de todos los actores confirma la pertenencia, de manera individualizada, de las empresas públicas en los polos de ciencia y tecnología del SI—SSPC.

En conclusión, podemos interpretar los resultados obtenidos en el sentido de verificación de las hipótesis formuladas en el caso específico de las cuatro empresas públicas estudiadas y ubicarlas en los polos del sistema. 


\subsection{FASE 4. ANÁLISIS COMPARATIVO ENTRE LOS HOSPITALES DE ALTA TECNOLOGÍA —GRUPO 4-DEL SI-SSPC}

Las hipótesis a contrastar en esta fase son las siguientes:

4.1. La generación de ciencia y de actividad científica de cada uno de los hospitales es significativamente diferente.

4.2. El número de personal de nivel superior se relaciona significativamente con los resultados científicos de los hospitales.

4.3. El valor del presupuesto se relaciona significativamente con los resultados de la actividad científica de los hospitales.

TABLA 7.29. Resumen de las variables analizadas en esta fase.

\begin{tabular}{|l|l||}
\hline Variable & Descripción de la variable \\
\hline \hline Presupuesto económico & $\begin{array}{l}\text { Se obtuvo a partir del presupuesto anual asignado } \\
\text { a los actores del estudio. }\end{array}$ \\
\hline \hline Personal de nivel superior & $\begin{array}{l}\text { Se obtuvo a partir del total de profesionales de } \\
\text { nivel superior de la plantilla de cada uno de los } \\
\text { actores. }\end{array}$ \\
\hline \hline Actividad científica & $\begin{array}{l}\text { Se obtuvo a partir de la suma de la actividad } \\
\text { científica divulgadora, participación u organzación } \\
\text { de congresos nacionales e internacionales, } \\
\text { simposios, cursos, jornadas, conferencias, actos, } \\
\text { seminarios y otros [no se incluye en esta variable } \\
\text { las publicaciones SCI u otras publicaciones que } \\
\text { producen los actores del sistema y que son } \\
\text { analizadas por separado]. }\end{array}$ \\
\hline \hline $\begin{array}{l}\text { Publicaciones de libros, } \\
\text { capítulos de libros y demás } \\
\text { publicaciones - otras } \\
\text { publicaciones- }\end{array}$ & $\begin{array}{l}\text { Se obtuvo a partir del número de publicaciones } \\
\text { efectuadas por los actores del estudio [se incluye } \\
\text { en esta variable todas las demás publicaciones } \\
\text { producidas por los actores del SI-SSPC } \\
\text { excluyendo las publicaciones SCI]. }\end{array}$ \\
\hline
\end{tabular}

Fuente: Elaboración propia. 
TABLA 7.30. Continuación de las variables analizadas en esta fase.

\begin{tabular}{|c|c|}
\hline Variable & Descripción de la variable \\
\hline Alumnos de medicina & $\begin{array}{l}\text { Se obtuvo a partir del número de alumnos de } \\
\text { graduación de la facultad de medicina admitidos } \\
\text { por los hospitales del Grupo } 4 \text {. }\end{array}$ \\
\hline$\underline{\text { Camas }}$ & $\begin{array}{l}\text { Se obtuvo a partir del número de camas que } \\
\text { poseen los hospitales del Grupo } 4 \text {. }\end{array}$ \\
\hline Ensayos clínicos & $\begin{array}{l}\text { Se obtuvo a partir del número de ensayos clínicos } \\
\text { realizados por los hospitales del Grupo } 4 .\end{array}$ \\
\hline $\begin{array}{l}\text { Factor de impactos de las } \\
\text { publicaciones SCI }\end{array}$ & $\begin{array}{l}\text { Se obtuvo a partir del factor de impacto de las } \\
\text { publicaciones del Science Citation Index-Journal } \\
\text { Citation Reports de los hospitales del Grupo } 4 .\end{array}$ \\
\hline $\begin{array}{l}\text { Médicos interno residente } \\
\text {-MIR- }\end{array}$ & $\begin{array}{l}\text { Se obtuvo a partir del número de MIR admitidos } \\
\text { por los hospitales del Grupo } 4 .\end{array}$ \\
\hline Proyectos de investigación & $\begin{array}{l}\text { Se obtuvo a partir del número de proyectos de } \\
\text { investigación desarrollados por los hospitales del } \\
\text { Grupo } 4 \text {. }\end{array}$ \\
\hline $\begin{array}{l}\text { Publicaciones de artículos } \\
\text { inéditos con factor de } \\
\text { impacto - publicaciones } \\
\text { SCI- }\end{array}$ & $\begin{array}{l}\text { Se obtuvo a partir del número de publicaciones } \\
\text { SCI-JCR efectuadas por los hospitales del Grupo } \\
4 \text { [solamente se incluye en esta variable los } \\
\text { artículos inéditos con factor de impacto del } \\
\text { SCI-JCR]. }\end{array}$ \\
\hline Tesis doctorales & $\begin{array}{l}\text { Se obtuvo a partir del número de tesis leídas y } \\
\text { aprobadas, dirigidas por miembros de los actores } \\
\text { del sistema. }\end{array}$ \\
\hline$\underline{\underline{T} \text { Trasplantes }}$ & $\begin{array}{l}\text { Se obtuvo a partir del número total de trasplantes } \\
\text { realizados por los hospitales del Grupo } 4 .\end{array}$ \\
\hline
\end{tabular}

Fuente: Elaboración propia.

\subsubsection{RESULTADO Y DESCRIPCIÓN DE LAS TABLAS}

Resultados de la generación de ciencia y de la actividad científica de los Hospitales del Grupo 4. 
TABLA 7.31. Resultados del número de publicaciones SCI y factor de impacto de esas publicaciones.

\begin{tabular}{|l|c|c|c|c|}
\hline Hospital & $\begin{array}{c}\text { Publicaciones } \\
\text { SCI }\end{array}$ & \% sobre el total & $\begin{array}{c}\text { Factor de impacto } \\
\text { SCI }\end{array}$ & \% sobre el total \\
\hline CSUB & 186 & 12,9 & 3,33 & 22,4 \\
\hline HUGTiP & 254 & 17,6 & 1,15 & 7,7 \\
\hline HC & 387 & 26,7 & 3,16 & 21,2 \\
\hline HSCSP & 139 & 9,6 & 2,76 & 18,5 \\
\hline CSUVH & 383 & 26,5 & 1,20 & 8,1 \\
\hline ICO & 98 & 6,8 & 3,29 & 22,1 \\
\hline TOTAL & 1447 & 100,0 & 14,89 & 100,0 \\
\hline
\end{tabular}

Fuente: Encuesta, preguntas 13 y 10. Número de respuestas: 12.

Del total de publicaciones SCI se destaca el hospital Clínic y los hospitales de la Vall d'Hebron con el 26,7\% y el 26,5\% respectivamente. En el factor de impacto de las publicaciones SCI se destaca el hospital de Bellvitge y el ICO con el $22,4 \%$ y el $22,1 \%$ respectivamente.

TABLA 7.32. Resultados del número de personal de nivel superior, de MIR y de alumnos de medicina.

\begin{tabular}{|l|c|c|c|c|c|c|}
\hline Hospital & $\begin{array}{c}\text { Personal } \\
\text { nivel } \\
\text { superior }\end{array}$ & $\begin{array}{c}\text { \% sobre el } \\
\text { total }\end{array}$ & No de MIR & $\begin{array}{c}\text { \% sobre el } \\
\text { total }\end{array}$ & $\begin{array}{c}\text { No de } \\
\text { alumnos } \\
\text { medicina }\end{array}$ & $\begin{array}{c}\% \text { sobre el } \\
\text { total }\end{array}$ \\
\hline CSUB & 698 & 17,8 & 197 & 15,0 & 322 & 13,4 \\
\hline HUGTiP & 241 & 6,1 & 154 & 11,7 & 247 & 10,3 \\
\hline HC & 757 & 19,3 & 256 & 19,5 & 225 & 9,4 \\
\hline HSJD & 224 & 5,7 & 51 & 3,9 & 405 & 16,8 \\
\hline HSCSP & 525 & 13,4 & 201 & 15,3 & 350 & 14,5 \\
\hline CSUVH & 1335 & 34,0 & 423 & 32,2 & 857 & 35,6 \\
\hline FP & 70 & 1,8 & 30 & 2,3 & - & - \\
\hline ICO & 80 & 2,0 & - & - & - & - \\
\hline TOTAL & 3930 & 100,0 & 1312 & 100,0 & 2406 & 100,0 \\
\hline
\end{tabular}

Fuente: Encuesta, preguntas 1, 11 y 7 . Número de respuestas: 21.

Del total de personal de nivel superior se destacan los hospitales de la Vall d'Hebron con el 34,0\% seguido del hospital Clínic con el 19,3\% del personal.

También del total de los MIR se destacan los hospitales de la Vall d'Hebron con el 32,2\% seguido del hospital Clínic con el 19,5\% y, en el total de alumnos 
de medicina también se destacan los hospitales de la Vall d'Hebron con el 35,6\% seguido del hospital de Sant Pau con el 14,5\%.

TABLA 7.33. Resultados del número de ensayos clínicos y de trasplantes realizados por cada hospital.

\begin{tabular}{|l|c|c|c|c|}
\hline Hospital & $\begin{array}{c}\text { No de ensayos } \\
\text { clínicos }\end{array}$ & \% sobre el total & $\begin{array}{c}\text { No de } \\
\text { trasplantes }\end{array}$ & \% sobre el total \\
\hline CSUB & 53 & 9,0 & 184 & 17,5 \\
\hline HUGTiP & 73 & 12,4 & 225 & 21,4 \\
\hline HC & 145 & 24,6 & 329 & 31,3 \\
\hline HSJD & 9 & 1,5 & 8 & 0,8 \\
\hline HSCSP & 147 & 25,0 & 111 & 10,6 \\
\hline CSUVH & 117 & 19,9 & 120 & 11,4 \\
\hline FP & 20 & 3,4 & 73 & 7,0 \\
\hline ICO & 25 & 4,2 & - & - \\
\hline TOTAL & 589 & 100,0 & 1050 & 100,0 \\
\hline
\end{tabular}

Fuente: Encuesta, preguntas 9 y 16. Número de respuestas: 15.

Del total de ensayos clínicos realizados se destaca el hospital de Sant Pau seguido del hospital Clínic con el 25,0\% y el 24,6\% respectivamente. En cuanto al número de trasplantes se destaca el hospital Clínic con el 31,3\% del total seguido del hospital Germans Trias i Pujol con el 21,4\%. 
TABLA 7.34. Resultados del número de otras publicaciones y de tesis doctorales generadas por los hospitales.

\begin{tabular}{|l|c|c|c|c|}
\hline Hospital & $\begin{array}{c}\text { No de otras } \\
\text { publicaciones }\end{array}$ & $\%$ sobre el total & $\begin{array}{c}\text { No de tesis } \\
\text { doctorales }\end{array}$ & \% sobre el total \\
\hline CSUB & 103 & 9,1 & 10 & 8,8 \\
\hline HUGTiP & 105 & 9,3 & 7 & 6,2 \\
\hline HC & 361 & 31,8 & 44 & 38,9 \\
\hline HSJD & 134 & 11,8 & 3 & 2,7 \\
\hline HSCSP & 113 & 10,0 & 22 & 19,5 \\
\hline CSUVH & 103 & 9,1 & 20 & 17,7 \\
\hline FP & 106 & 9,3 & 3 & 2,7 \\
\hline ICO & 109 & 9,6 & 4 & 3,5 \\
\hline TOTAL & 1134 & 100,0 & 113 & 100,0 \\
\hline
\end{tabular}

Fuente: Encuesta, preguntas 14 y 15. Número de respuestas: 16.

Del total de otras publicaciones se destaca el hospital Clínic con el 31,8\% del total seguido del hospital Sant Joan de Déu con el 11,8\%. Del total de tesis doctorales dirigidas por médicos de cada hospital también se destaca el hospital Clínic con el 38,9\% del total, seguido del hospital de Sant Pau con el 19,5\%.

TABLA 7.35. Resultados del número de actividad científica y de proyectos de investigación producidos por los hospitales.

\begin{tabular}{|l|c|c|c|c|}
\hline Hospital & $\begin{array}{c}\text { No de actividad } \\
\text { científica }\end{array}$ & \% sobre el total & $\begin{array}{c}\text { No de proyectos } \\
\text { de investigación }\end{array}$ & \% sobre el total \\
\hline CSUB & 744 & 15,4 & 40 & 9,3 \\
\hline HUGTiP & 761 & 15,7 & 15 & 3,5 \\
\hline HC & 530 & 10,9 & 26 & 6,1 \\
\hline HSJD & 485 & 10,0 & 6 & 1,4 \\
\hline HSCSP & 463 & 9,6 & 60 & 14,0 \\
\hline CSUVH & 908 & 18,7 & 248 & 57,8 \\
\hline FP & 275 & 5,7 & 7 & 1,6 \\
\hline ICO & 678 & 14,0 & 27 & 6,3 \\
\hline TOTAL & 4844 & 100,0 & 429 & 100,0 \\
\hline
\end{tabular}

Fuente: Encuesta, preguntas 6 y 12. Número de respuestas: 16. 
Del total de la actividad científica producida por los hospitales se destacan los hospitales de la Vall d'Hebron con el 18,7\% seguido por el hospital Germans Trias i Pujol con el 15,7\%. Del total de proyectos de investigación producidos por los hospitales se destacan los hospitales de la Vall d'Hebron con el 57,8\% seguido por el hospital de Sant Pau con el 14,0\%.

TABLA 7.36. Resultados del presupuesto económico y del número de camas de cada unos de los hospitales.

\begin{tabular}{|l|c|c|c|c|}
\hline Hospital & $\begin{array}{c}\text { Presupuesto } \\
\text { económico }\end{array}$ & $\%$ sobre el total & No de camas & \% sobre el total \\
\hline CSUB & 23.608 .228 .000 & 15,9 & 859 & 16,8 \\
\hline HUGTiP & 13.024 .180 .000 & 8,8 & 573 & 11,2 \\
\hline HC & 28.751 .891 .000 & 19,4 & 855 & 16,7 \\
\hline HSJD & 7.787 .701 .000 & 5,3 & 363 & 7,1 \\
\hline HSCSP & 21.650 .800 .000 & 14,6 & 740 & 14,5 \\
\hline CSUVH & 45.192 .332 .000 & 30,5 & 1443 & 28,2 \\
\hline FP & 4.500 .000 .000 & 3,0 & 165 & 3,2 \\
\hline ICO & 3.500 .000 .000 & 2,4 & 118 & 2,3 \\
\hline TOTAL & 148.015 .132 .000 & 100,0 & 5116 & 100,0 \\
\hline
\end{tabular}

Fuente: Encuesta, preguntas 4 y 8. Número de respuestas: 16.

Del total del presupuesto económico destinado a los hospitales se destacan los hospitales de la Vall d'Hebron con el 30,5\% seguidos por el hospital Clínic con el 19,4\%. Del total de las camas hospitalarias se destacan los hospitales de la Vall d'Hebron con el 28,2\% seguidos por el hospital de Bellvitge con el 16,8\%. 
TABLA 7.37. Resultados de todas las variables de los hospitales.

\begin{tabular}{|l|c|c|c|c|c|c|c|c|c|}
\hline Variable Hospital & $\begin{array}{c}\text { CSUB } \\
\%\end{array}$ & $\begin{array}{c}\text { HUGTiP } \\
\%\end{array}$ & $\begin{array}{c}\text { HC } \\
\%\end{array}$ & $\begin{array}{c}\text { HSJD } \\
\%\end{array}$ & $\begin{array}{c}\text { HSCSP } \\
\%\end{array}$ & $\begin{array}{c}\text { CSUVH } \\
\%\end{array}$ & $\begin{array}{c}\text { FP } \\
\%\end{array}$ & $\begin{array}{c}\text { ICO } \\
\%\end{array}$ & TOTAL \\
\hline Presupuesto & 15,9 & 8,8 & 19,4 & 5,3 & 14,6 & 30,5 & 3,0 & 2,4 & 100,0 \\
\hline No de camas $^{0} 16,8$ & 11,2 & 16,7 & 7,1 & 14,5 & 28,2 & 3,2 & 2,3 & 100,0 \\
\hline $\begin{array}{l}\text { Recurso humanos } \\
\text { nivel superior }\end{array}$ & 17,8 & 6,1 & 19,3 & 5,7 & 13,4 & 34,0 & 1,8 & 2,0 & 100,0 \\
\hline No de MIR $^{0}$ & 15,0 & 11,7 & 19,5 & 3,9 & 15,3 & 32,2 & 2,3 & - & 100,0 \\
\hline $\begin{array}{l}N^{0} \text { alumnos de } \\
\text { medicina }\end{array}$ & 13,4 & 10,3 & 9,4 & 16,8 & 14,5 & 35,6 & - & - & 100,0 \\
\hline Publicaciones SCI & 12,9 & 17,6 & 26,7 & - & 9,6 & 26,5 & - & 6,8 & 100,0 \\
\hline $\begin{array}{l}\text { Factor de } \\
\text { impacto SCI }\end{array}$ & 22,4 & 7,7 & 21,2 & - & 18,5 & 8,1 & - & 22,1 & 100,0 \\
\hline $\begin{array}{l}\text { No otras } \\
\text { publicaciones }\end{array}$ & 9,1 & 9,3 & 31,8 & 11,8 & 10,0 & 9,1 & 9,3 & 9,6 & 100,0 \\
\hline $\begin{array}{l}\text { No de tesis } \\
\text { doctorales }\end{array}$ & 8,8 & 6,2 & 38,9 & 2,7 & 19,5 & 17,7 & 2,7 & 3,5 & 100,0 \\
\hline $\begin{array}{l}N^{0} \text { actividad } \\
\text { científica }\end{array}$ & 15,4 & 15,7 & 10,9 & 10,0 & 9,6 & 18,7 & 5,7 & 14,0 & 100,0 \\
\hline $\begin{array}{l}N^{0} \text { proyectos } \\
\text { investigación }\end{array}$ & 9,3 & 3,5 & 6,1 & 1,4 & 14,0 & 57,8 & 1,6 & 6,3 & 100,0 \\
\hline $\begin{array}{l}\text { No de ensayos } \\
\text { clínicos }\end{array}$ & 9,0 & 12,4 & 24,6 & 1,5 & 25,0 & 19,9 & 3,4 & 4,2 & 100,0 \\
\hline$N^{0}$ de trasplantes & 17,5 & 21,4 & 31,3 & 0,8 & 10,6 & 11,4 & 7,0 & - & 100,0 \\
\hline
\end{tabular}

Fuente: Elaboración propia a partir de la Encuesta.

En esta tabla se observa que los hospitales de la Vall d'Hebron tienen el mayor presupuesto, número de camas, personal de nivel superior, MIR, alumnos de medicina, número de actividad científica y número de proyectos de investigación.

El hospital Clínic hace el mayor número de trasplantes, publica más artículos SCI, otras publicaciones y también produce el mayor número de tesis doctorales. Bellvitge posee el mayor factor de impacto de las publicaciones SCI y Sant Pau produce el mayor número de ensayos clínicos. 
TABLA 7.38. Resultados de las publicaciones SCI y otras publicaciones por personal de nivel superior.

\begin{tabular}{|l|c|c|c|c|c|}
\hline Hospital & $\begin{array}{c}\text { Personal de } \\
\text { nivel superior }\end{array}$ & $\begin{array}{c}\text { Publicaciones } \\
\text { SCI }\end{array}$ & PSCI/PNS & $\begin{array}{c}\text { Otras } \\
\text { publicaciones }\end{array}$ & OP/PNS \\
\hline CSUB & 698 & 186 & 0,266 & 103 & 0,148 \\
\hline HUGTiP & 241 & 254 & 1,054 & 105 & 0,436 \\
\hline HC & 757 & 387 & 0,511 & 361 & 0,477 \\
\hline HSJD & 224 & - & - & 134 & 0,598 \\
\hline HSCSP & 525 & 139 & 0,265 & 113 & 0,215 \\
\hline CSUVH & 1335 & 383 & 0,287 & 103 & 0,077 \\
\hline FP & 70 & - & - & 106 & 1,514 \\
\hline ICO & 80 & 98 & 1,225 & 109 & 1,363 \\
\hline
\end{tabular}

Fuente: Encuesta, preguntas 1, 13 y 14. Número de respuestas: 22.

En esta tabla se observa que el hospital Clínic publica el mayor número de artículos SCI pero el mayor índice de publicaciones-personal de nivel superior tiene el ICO. También en otras publicaciones el hospital Clínic produce el mayor número pero el mayor índice publicaciones_-personal de nivel superior tiene la Fundació Puigvert.

TABLA 7.39. Resultados de las publicaciones SCI y otras publicaciones por el presupuesto.

\begin{tabular}{|l|c|c|c|c|c|}
\hline Hospital & $\begin{array}{c}\text { Presupuesto } \\
\text { económico* }\end{array}$ & $\begin{array}{c}\text { Publicaciones } \\
\text { SCI }\end{array}$ & $\begin{array}{c}\text { PSCI } \\
\text { /PRESUP. }\end{array}$ & $\begin{array}{c}\text { Otras } \\
\text { publicaciones }\end{array}$ & OP/PRESUP. \\
\hline CSUB & 23608 & 186 & 0,0079 & 103 & 0,0044 \\
\hline HUGTiP & 13024 & 254 & 0,0195 & 105 & 0,0081 \\
\hline HC & 28752 & 387 & 0,0135 & 361 & 0,0126 \\
\hline HSJD & 7788 & - & - & 134 & 0,0172 \\
\hline HSCSP & 21651 & 139 & 0,0064 & 113 & 0,0052 \\
\hline CSUVH & 45192 & 383 & 0,0085 & 103 & 0,0023 \\
\hline FP & 4500 & - & - & 106 & 0,0236 \\
\hline ICO & 3500 & 98 & 0,0280 & 109 & 0,0311 \\
\hline$*$ Presupuesto económico expresado en millones de pesetas. & \\
\hline
\end{tabular}

Fuente: Encuesta, preguntas 4, 13 y 14. Número de respuestas: 22. 
En relación con el presupuesto quien más publica es en los dos casos estudiados, artículos SCI y otras publicaciones el ICO.

TABLA 7.40. Resultados de la actividad científica y tesis doctorales por el personal de nivel superior.

\begin{tabular}{|l|c|c|c|c|c|}
\hline Hospital & $\begin{array}{c}\text { Personal } \\
\text { nivel superior }\end{array}$ & $\begin{array}{c}\text { Actividad } \\
\text { científica }\end{array}$ & AC/PNS & $\begin{array}{c}\text { Tesis } \\
\text { doctorales }\end{array}$ & TD/PNS \\
\hline CSUB & 698 & 744 & 1,07 & 10 & 0,0143 \\
\hline HUGTiP & 241 & 761 & 3,16 & 7 & 0,0290 \\
\hline HC & 757 & 530 & 0,70 & 44 & 0,0581 \\
\hline HSJD & 224 & 485 & 2,17 & 3 & 0,0134 \\
\hline HSCSP & 525 & 463 & 0,88 & 22 & 0,0419 \\
\hline CSUVH & 1335 & 908 & 0,68 & 20 & 0,0150 \\
\hline FP & 70 & 275 & 3,93 & 3 & 0,0429 \\
\hline ICO & 80 & 678 & 8,48 & 4 & 0,0500 \\
\hline
\end{tabular}

Fuente: Encuesta, preguntas 1, 6 y 15. Número de respuestas: 24.

En esta tabla se observa que los hospitales de la Vall d'Hebron producen el mayor número de actividad científica pero el mejor índice actividad científica—personal de nivel superior tiene el ICO. Con relación a la producción de tesis doctorales el hospital Clínic supera a los demás hospitales, tanto por el número de tesis doctorales producida como por el índice tesis doctorales—-personal de nivel superior.

TABLA 7.41. Resultados de la actividad científica y tesis doctorales por el presupuesto.

\begin{tabular}{|l|c|c|c|c|c|}
\hline Hospital & $\begin{array}{c}\text { Presupuesto } \\
\text { económico* }\end{array}$ & $\begin{array}{c}\text { Actividad } \\
\text { científica }\end{array}$ & AC/PRESUP. & $\begin{array}{c}\text { Tesis } \\
\text { doctorales }\end{array}$ & TD/PRESUP. \\
\hline CSUB & 23608 & 744 & 0,0315 & 10 & 0,00042 \\
\hline HUGTiP & 13024 & 761 & 0,0584 & 7 & 0,00054 \\
\hline HC & 28752 & 530 & 0,0184 & 44 & 0,00153 \\
\hline HSJD & 7788 & 485 & 0,0623 & 3 & 0,00039 \\
\hline HSCSP & 21651 & 463 & 0,0214 & 22 & 0,00102 \\
\hline CSUVH & 45192 & 908 & 0,0201 & 20 & 0,00044 \\
\hline FP & 4500 & 275 & 0,0611 & 3 & 0,00067 \\
\hline ICO & 3500 & 678 & 0,1937 & 4 & 0,00114 \\
\hline * Presupuesto económico expresado en millones de pesetas. & \\
\hline
\end{tabular}

Fuente: Encuesta, preguntas 4, 6 y 15. Número de respuestas: 24. 
Con relación al presupuesto el mayor índice actividad científica-presupuesto tiene con diferencia el ICO y el mayor índice tesis doctorales-presupuesto tiene el hospital Clínic.

TABLA 7.42. Resultados de los trasplantes y las camas por el personal de nivel superior.

\begin{tabular}{|l|c|c|c|c|c|}
\hline Hospital & $\begin{array}{c}\text { Total personal } \\
\text { nivel superior }\end{array}$ & Trasplantes & TR/PNS & Camas & CA/PNS \\
\hline CSUB & 698 & 184 & 0,264 & 859 & 33,82 \\
\hline HUGTiP & 241 & 225 & 0,934 & 573 & 54,04 \\
\hline HC & 757 & 329 & 0,435 & 855 & 37,98 \\
\hline HSJD & 224 & 8 & 0,036 & 363 & 34,77 \\
\hline HSCSP & 525 & 111 & 0,211 & 740 & 41,24 \\
\hline CSUVH & 1335 & 120 & 0,090 & 1443 & 33,85 \\
\hline FP & 70 & 73 & 1,043 & 165 & 64,29 \\
\hline ICO & 80 & - & - & 118 & 43,75 \\
\hline
\end{tabular}

Fuente: Encuesta, preguntas 1, 16 y 8. Número de respuestas: 23.

En esta tabla se observa que el hospital Clínic hace el mayor número de trasplantes de los hospitales del Grupo 4, pero el mayor índice trasplante-personal de nivel superior lo tiene la Fundació Puigvert. Con relación a las camas los hospitales de la Vall d'Hebron tienen el mayor número pero el mayor índice camas-personal de nivel superior tiene la Fundació Puigvert y el menor índice lo tiene el Bellvitge.

TABLA 7.43. Resultados de los trasplantes y las camas por el presupuesto.

\begin{tabular}{|l|c|c|c|c|c|}
\hline Hospital & $\begin{array}{c}\text { Presupuesto } \\
\text { económico* }\end{array}$ & Trasplantes & TR/PRESUP. & Camas & CA/PRESUP. \\
\hline CSUB & 23608 & 184 & 0,0078 & 859 & 0,0364 \\
\hline HUGTiP & 13024 & 225 & 0,0173 & 573 & 0,0440 \\
\hline HC & 28752 & 329 & 0,0114 & 855 & 0,0297 \\
\hline HSJD & 7788 & 8 & 0,0010 & 363 & 0,0466 \\
\hline HSCSP & 21651 & 111 & 0,0051 & 740 & 0,0342 \\
\hline CSUVH & 45192 & 120 & 0,0027 & 1443 & 0,0320 \\
\hline FP & 4500 & 73 & 0,0162 & 165 & 0,0367 \\
\hline ICO & 3500 & - & - & 118 & 0,0337 \\
\hline * Presupuesto económico expresado en millones de pesetas. \\
\hline
\end{tabular}

Fuente: Encuesta, preguntas 4, 16 y 8. Número de respuestas: 23. 
Con relación al presupuesto el mayor índice trasplantes-presupuesto lo tiene el hospital Germans Trias i Pujol y el menor lo tiene el hospital Sant Joan de Déu.

En relación con las camas el mayor índice camas-presupuesto lo tiene el hospital Sant Joan de Déu y el menor índice lo tiene el hospital Clínic.

TABLA 7.44. Resultados de los proyectos de investigación y ensayos clínicos por el personal de nivel superior.

\begin{tabular}{|l|c|c|c|c|c|}
\hline Hospital & $\begin{array}{c}\text { Personal } \\
\text { nivel superior }\end{array}$ & $\begin{array}{c}\text { Proyectos de } \\
\text { investigación }\end{array}$ & PI/PNS & $\begin{array}{c}\text { Ensayos } \\
\text { clínicos }\end{array}$ & EC/PNS \\
\hline CSUB & 698 & 40 & 0,0573 & 53 & 0,0759 \\
\hline HUGTiP & 241 & 15 & 0,0622 & 73 & 0,3029 \\
\hline HC & 757 & 26 & 0,0343 & 145 & 0,1915 \\
\hline HSJD & 224 & 6 & 0,0268 & 9 & 0,0402 \\
\hline HSCSP & 525 & 60 & 0,1143 & 147 & 0,2800 \\
\hline CSUVH & 1335 & 248 & 0,1858 & 117 & 0,0876 \\
\hline FP & 70 & 7 & 0,1000 & 20 & 0,2857 \\
\hline ICO & 80 & 27 & 0,3375 & 25 & 0,3125 \\
\hline
\end{tabular}

Fuente: Encuesta, preguntas 1, 12 y 9. Número de respuestas: 24.

En esta tabla se observa que los hospitales de la Vall d'Hebron producen el mayor número de proyectos de investigación el mayor índice proyecto de investigación-personal de nivel superior lo tiene el ICO.

Con relación a los ensayos clínicos es el hospital de Sant Pau el que produce el mayor número pero es de nuevo el ICO el que tiene el mayor índice ensayos clínicos-personal de nivel superior. 
TABLA 7.45. Resultados de los proyectos de investigación y ensayos clínicos por el presupuesto.

\begin{tabular}{|l|c|c|c|c|c|}
\hline Hospital & $\begin{array}{c}\text { Presupuesto } \\
\text { económico* }\end{array}$ & $\begin{array}{c}\text { Proyectos de } \\
\text { investigación }\end{array}$ & PI/PRESUP. & $\begin{array}{c}\text { Ensayos } \\
\text { clínicos }\end{array}$ & EC/PRESUP. \\
\hline CSUB & 23608 & 40 & 0,0017 & 53 & 0,0022 \\
\hline HUGTiP & 13024 & 15 & 0,0012 & 73 & 0,0056 \\
\hline HC & 28752 & 26 & 0,0009 & 145 & 0,0050 \\
\hline HSJD & 7788 & 6 & 0,0008 & 9 & 0,0012 \\
\hline HSCSP & 21651 & 60 & 0,0028 & 147 & 0,0068 \\
\hline CSUVH & 45192 & 248 & 0,0055 & 117 & 0,0026 \\
\hline FP & 4500 & 7 & 0,0016 & 20 & 0,0044 \\
\hline ICO & 3500 & 27 & 0,0077 & 25 & 0,0071 \\
\hline * Presupuesto económico expresado en millones de pesetas. \\
\hline
\end{tabular}

Fuente: Encuesta, preguntas 4, 12 y 9. Número de respuestas: 24 .

Con relación al presupuesto el mayor índice proyecto de investigaciónpresupuesto lo tiene el ICO y en relación ensayos clínicos-presupuesto el mayor índice lo tiene el hospital de Sant Pau.

TABLA 7.46. Resultados de los MIR y alumnos de medicina por el personal de nivel superior.

\begin{tabular}{|l|c|c|c|c|c|}
\hline Hospital & $\begin{array}{c}\text { Personal } \\
\text { nivel superior }\end{array}$ & MIR & MIR/PNS & $\begin{array}{c}\text { Alumnos } \\
\text { medicina }\end{array}$ & AM/PNS \\
\hline CSUB & 698 & 197 & 0,282 & 322 & 0,461 \\
\hline HUGTiP & 241 & 154 & 0,639 & 247 & 1,025 \\
\hline HC & 757 & 256 & 0,338 & 225 & 0,297 \\
\hline HSJD & 224 & 51 & 0,228 & 405 & 1,808 \\
\hline HSCSP & 525 & 201 & 0,383 & 350 & 0,667 \\
\hline CSUVH & 1335 & 423 & 0,317 & 857 & 0,642 \\
\hline FP & 70 & 30 & 0,429 & - & - \\
\hline ICO & 80 & - & - & - & - \\
\hline
\end{tabular}

Fuente: Encuesta, preguntas 1, 11 y 7 . Número de respuestas: 21.

En esta tabla se observa que el mayor número de MIR tienen los hospitales de la Vall d'Hebron y el mayor índice MIR — personal de nivel superior lo tiene el hospital Germans Trias i Pujol. Con relación a los alumnos de medicina los hospitales de la Vall d'Hebron también tienen el mayor número pero el mayor índice alumnos de medicina-personal de nivel superior lo tiene el hospital Sant Joan de Déu. 
TABLA 7.47. Resultados de los MIR y alumnos de medicina por el presupuesto.

\begin{tabular}{|l|c|c|c|c|c|}
\hline Hospital & $\begin{array}{c}\text { Presupuesto } \\
\text { económico* }\end{array}$ & MIR & MIR/PRESUP. & $\begin{array}{c}\text { Alumnos } \\
\text { medicina }\end{array}$ & AM/PRESUP. \\
\hline CSUB & 23608 & 197 & 0,0083 & 322 & 0,0136 \\
\hline HUGTiP & 13024 & 154 & 0,0118 & 274 & 0,0190 \\
\hline HC & 28752 & 256 & 0,0089 & 225 & 0,0078 \\
\hline HSJD & 7788 & 51 & 0,0065 & 405 & 0,0520 \\
\hline HSCSP & 21651 & 201 & 0,0093 & 350 & 0,0162 \\
\hline CSUVH & 45192 & 423 & 0,0094 & 857 & 0,0190 \\
\hline FP & 4500 & 30 & 0,0067 & - & - \\
\hline ICO & 3500 & - & - & - & - \\
\hline * Presupuesto económico expresado en millones de pesetas. \\
\hline
\end{tabular}

Fuente: Encuesta, preguntas 4, 11 y 7. Número de respuestas: 21.

Con relación a MIR — presupuesto el mayor índice lo tiene el hospital Germans Trias i Pujol y en relación con el índice alumnos de medicina-presupuesto el mayor índice lo tiene el hospital Sant Joan de Déu.

TABLA 7.48. Estadístico de las variables de los hospitales.

\begin{tabular}{|l|c|c|}
\hline Variable & Media & Desviación típica \\
\hline Actividad científica & 605,50 & 203,50 \\
\hline Presupuesto & $1,85 \mathrm{E}+10$ & $1,42 \mathrm{E}+10$ \\
\hline Personal de nivel superior & 491,25 & 432,11 \\
\hline MIR & 187,43 & 132,28 \\
\hline Alumnos de medicina & 401,00 & 233,02 \\
\hline Otras publicaciones & 141,75 & 89,17 \\
\hline Publicaciones SCI & 241,17 & 122,90 \\
\hline Tesis doctorales & 14,13 & 14,18 \\
\hline Ensayos clínicos & 73,63 & 56,32 \\
\hline Trasplantes & 150,00 & 105,94 \\
\hline Proyectos de investigación & 53,63 & 80,55 \\
\hline Camas & 639,50 & 435,61 \\
\hline
\end{tabular}

Fuente: Elaboración propia a partir de la Encuesta. 
En esta tabla se observa que para todas las variables con excepción de presupuesto económico, tesis doctorales y proyectos de investigación, la media es mayor que la desviación típica.

TABLA 7.49. Comparación de los estadísticos de las variables de los hospitales con todos los actores.

\begin{tabular}{|l|c|c|c|c|}
\hline Variable & $\begin{array}{c}\text { Media de los } \\
\text { hospitales }\end{array}$ & $\begin{array}{c}\text { Media } \\
\text { de todos los } \\
\text { actores }\end{array}$ & $\begin{array}{c}\text { Desviación } \\
\text { típica de los } \\
\text { hospitales }\end{array}$ & $\begin{array}{c}\text { Desviación } \\
\text { típica de todos los } \\
\text { actores }\end{array}$ \\
\hline $\begin{array}{l}\text { Actividad } \\
\text { científica }\end{array}$ & 605,50 & 282,26 & 203,50 & 348,02 \\
\hline $\begin{array}{l}\text { Otras } \\
\text { publicaciones }\end{array}$ & 141,75 & 72,48 & 89,17 & 91,19 \\
\hline $\begin{array}{l}\text { Personal de } \\
\text { nivel superior }\end{array}$ & 491,25 & 1321,74 & 432,11 & 2052,38 \\
\hline $\begin{array}{l}\text { Presupuesto } \\
\text { económico }\end{array}$ & $1,85 \mathrm{E}+10$ & $6,79 \mathrm{E}+10$ & $1,42+10$ & $1,31 \mathrm{E}+11$ \\
\hline
\end{tabular}

Fuente: Elaboración propia a partir de la Encuesta.

En esta tabla se observa que la media de la actividad científica y otras publicaciones de los hospitales es mayor que la de todos los actores y su desviación es menor que la media de la variable de los hospitales y menor que la desviación típica de todos los actores.

Con relación al personal de nivel superior y el presupuesto económico la media de los hospitales es menor que la media de todos los actores y su desviación típica es menor que la media de la variable de los hospitales y menor que la desviación típica de todos los actores, por lo que se puede afirmar que el conjunto de los hospitales de alta tecnología presenta una mayor homogeneidad en sus actividades.

En otras palabras, los hospitales producen más actividad científica y otras publicaciones con menor número de personal de nivel superior y menor presupuesto económico y con mas homogeneidad en comparación con todos los actores del sistema. 
TABLA 7.50. Análisis de Regresión Lineal de actividad científica.

\begin{tabular}{|l|c|c|c|c|}
\hline $\begin{array}{l}\text { Variables } \\
\text { predictoras }\end{array}$ & $\begin{array}{c}\mathrm{R} \\
\text { Correlación de } \\
\text { Pearson }\end{array}$ & $\begin{array}{c}\mathrm{R}^{2} \\
\text { Coeficiente de } \\
\text { determinación }\end{array}$ & $\mathrm{R}^{2}$ corregida & $\begin{array}{c}\text { Significación del } \\
\text { cambio en } \mathrm{F}\end{array}$ \\
\hline MIR & 0,746 & 0,556 & 0,467 & 0,054 \\
\hline $\begin{array}{l}\text { Personal de } \\
\text { nivel superior }\end{array}$ & 0,588 & 0,345 & 0,236 & 0,126 \\
\hline $\begin{array}{l}\text { Presupuesto } \\
\text { económico }\end{array}$ & 0,569 & 0,324 & 0,211 & 0,141 \\
\hline
\end{tabular}

Fuente: Elaboración propia a partir de la Encuesta.

En esta tabla se observa que para el modelo propuesto el coeficiente 0,556 indica que por cada unidad de cambio en MIR se produce un cambio de 0,556 unidades [55,6\%] en la actividad científica con la significación del 0,054 [94,6\%]. El coeficiente 0,345 indica que por cada unidad de cambio en personal de nivel superior se produce un cambio de 0,345 unidades [34,5\%] en la actividad científica con la significación del $0,126[87,4 \%]$ y el coeficiente 0,324 indica que por cada unidad de cambio en el presupuesto económico se produce un cambio de 0,324 unidades $[32,4 \%]$ en la actividad científica con la significación del 0,141 [85,9\%].

TABLA 7.51. Análisis de Regresión Lineal de camas.

\begin{tabular}{|l|c|c|c|c|}
\hline $\begin{array}{l}\text { Variables } \\
\text { predictoras }\end{array}$ & $\begin{array}{c}\mathrm{R} \\
\text { Correlación de } \\
\text { Pearson }\end{array}$ & $\begin{array}{c}\mathrm{R}^{2} \\
\text { Coeficiente de } \\
\text { determinación }\end{array}$ & $\mathrm{R}^{2}$ corregida & $\begin{array}{c}\text { Significación del } \\
\text { cambio en F }\end{array}$ \\
\hline MIR & 0,986 & 0,972 & 0,966 & 0,000 \\
\hline $\begin{array}{l}\text { Personal de } \\
\text { nivel superior }\end{array}$ & 0,978 & 0,957 & 0,950 & 0,000 \\
\hline $\begin{array}{l}\text { Presupuesto } \\
\text { económico }\end{array}$ & 0,988 & 0,976 & 0,971 & 0,000 \\
\hline
\end{tabular}

Fuente: Elaboración propia a partir de la Encuesta.

En esta tabla se observa que para el modelo propuesto el coeficiente 0,972 indica que por cada unidad de cambio en MIR se produce un cambio de 0,972 unidades $[97,2 \%]$ en el número de camas con la significación del 0,000 $[100,0 \%]$.

El coeficiente 0,957 indica que por cada unidad de cambio en personal de nivel superior se produce un cambio de 0,957 unidades [95,7\%] en el número 
de camas con la significación del $0,000[100,0 \%]$ y el coeficiente 0,976 indica que por cada unidad de cambio en el presupuesto económico se produce un cambio de 0,976 unidades $[97,6 \%]$ en el número de camas con la significación del $0,000[100,0 \%]$.

TABLA 7.52. Análisis de Regresión Lineal ensayos clínicos.

\begin{tabular}{|l|c|c|c|c|}
\hline $\begin{array}{l}\text { Variables } \\
\text { predictoras }\end{array}$ & $\begin{array}{c}\mathrm{R} \\
\text { Correlación de } \\
\text { Pearson }\end{array}$ & $\begin{array}{c}\mathrm{R}^{2} \\
\text { Coeficiente de } \\
\text { determinación }\end{array}$ & $\mathrm{R}^{2}$ corregida & $\begin{array}{c}\text { Significación del } \\
\text { cambio en F }\end{array}$ \\
\hline MIR & 0,734 & 0,538 & 0,446 & 0,061 \\
\hline $\begin{array}{l}\text { Personal de } \\
\text { nivel superior }\end{array}$ & 0,668 & 0,446 & 0,354 & 0,070 \\
\hline $\begin{array}{l}\text { Presupuesto } \\
\text { económico }\end{array}$ & 0,747 & 0,557 & 0,484 & 0,033 \\
\hline
\end{tabular}

Fuente: Elaboración propia a partir de la Encuesta.

En esta tabla se observa que para el modelo propuesto el coeficiente 0,538 indica que por cada unidad de cambio en MIR se produce un cambio de 0,538 unidades $[53,8 \%]$ en el número de ensayos clínicos con la significación del $0,061[93,9 \%]$.

El coeficiente 0,446 indica que por cada unidad de cambio en personal de nivel superior se produce un cambio de 0,446 unidades [44,6\%] en el número de ensayos clínicos con la significación del $0,070[93,0 \%$ y el coeficiente 0,557 indica que por cada unidad de cambio en el presupuesto económico se produce un cambio de 0,557 unidades [55,7\%] en el número de ensayos clínicos con la significación del 0,033 [96,7\%].

TABLA 7.53. Análisis de Regresión Lineal de proyectos de investigación.

\begin{tabular}{|l|c|c|c|c|}
\hline $\begin{array}{l}\text { Variables } \\
\text { predictoras }\end{array}$ & $\begin{array}{c}\mathrm{R} \\
\text { Correlación de } \\
\text { Pearson }\end{array}$ & $\begin{array}{c}\mathrm{R}^{2} \\
\text { Coeficiente de } \\
\text { determinación }\end{array}$ & $\mathrm{R}^{2}$ corregida & $\begin{array}{c}\text { Significación del } \\
\text { cambio en F }\end{array}$ \\
\hline MIR & 0,862 & 0,743 & 0,691 & 0,013 \\
\hline $\begin{array}{l}\text { Personal de } \\
\text { nivel superior }\end{array}$ & 0,850 & 0,722 & 0,676 & 0,008 \\
\hline $\begin{array}{l}\text { Presupuesto } \\
\text { económico }\end{array}$ & 0,826 & 0,682 & 0,629 & 0,012 \\
\hline
\end{tabular}

Fuente: Elaboración propia a partir de la Encuesta. 
En esta tabla se observa que para el modelo propuesto el coeficiente 0,743 indica que por cada unidad de cambio en MIR se produce un cambio de 0,743 unidades $[74,3 \%]$ en el número de proyectos de investigación con la significación del $0,013[98,7 \%]$.

El coeficiente 0,722 indica que por cada unidad de cambio en personal de nivel superior se produce un cambio de 0,722 unidades $[72,2 \%]$ en el número de proyectos de investigación con la significación del 0,008 [99,9\%] y el coeficiente 0,682 indica que por cada unidad de cambio en el presupuesto económico se produce un cambio de 0,682 unidades $[68,2 \%]$ en el número de proyectos de investigación con la significación del 0,012 [98,8\%].

TABLA 7.54. Análisis de Regresión Lineal de trasplantes.

\begin{tabular}{|l|c|c|c|c|}
\hline $\begin{array}{l}\text { Variables Medidas } \\
\text { predictoras }\end{array}$ & $\begin{array}{c}\mathrm{R} \\
\text { Correlación de } \\
\text { Pearson }\end{array}$ & $\begin{array}{c}\mathrm{R}^{2} \\
\text { Coeficiente de } \\
\text { determinación }\end{array}$ & $\mathrm{R}^{2}$ corregida & $\begin{array}{c}\text { Significación del } \\
\text { cambio en } \mathrm{F}\end{array}$ \\
\hline MIR & 0,404 & 0,163 & $-0,004$ & 0,368 \\
\hline $\begin{array}{l}\text { Personal de } \\
\text { nivel superior }\end{array}$ & 0,291 & 0,084 & $-0,099$ & 0,527 \\
\hline $\begin{array}{l}\text { Presupuesto } \\
\text { económico }\end{array}$ & 0,370 & 0,137 & $-0,036$ & 0,414 \\
\hline
\end{tabular}

Fuente: Elaboración propia a partir de la Encuesta.

En esta tabla se observa que para el modelo propuesto el coeficiente 0,163 indica que por cada unidad de cambio en MIR se produce un cambio de 0,163 unidades $[16,3 \%]$ en el número de trasplantes con la significación del 0,368 $[63,2 \%]$. El coeficiente 0,084 indica que por cada unidad de cambio en personal de nivel superior se produce un cambio de 0,084 unidades $[8,4 \%]$ en el número de trasplantes con la significación del 0,527 [47,3\%] y el coeficiente 0,137 indica que por cada unidad de cambio en el presupuesto económico se produce un cambio de 0,137 unidades $[13,7 \%]$ en el número de trasplantes con la significación del $0,414[58,6 \%]$.

Como se puede comprobar los resultados estadísticos muestran unos valores de $\mathrm{R}^{2}$ corregida negativo para los tres casos indicando una relación inversa entre trasplantes-MIR, trasplantes-personal de nivel superior y trasplantespresupuesto económico, por lo tanto la no-validez de la hipótesis.

En otras palabras, el hecho de que los hospitales tengan una mayor plantilla de MIR, de personal de nivel superior y un mayor presupuesto económico no hace prever que realicen un mayor número de trasplantes. 
TABLA 7.55. Análisis de Regresión Lineal de tesis doctorales.

\begin{tabular}{|l|c|c|c|c|}
\hline $\begin{array}{l}\text { Variables } \\
\text { predictoras }\end{array}$ & $\begin{array}{c}\mathrm{R} \\
\text { Correlación de } \\
\text { Pearson }\end{array}$ & $\begin{array}{c}\mathrm{R}^{2} \\
\text { Coeficiente de } \\
\text { determinación }\end{array}$ & $\mathrm{R}^{2}$ corregida & $\begin{array}{c}\text { Significación del } \\
\text { cambio en } \mathrm{F}\end{array}$ \\
\hline MIR & 0,602 & 0,363 & 0,235 & 0,152 \\
\hline $\begin{array}{l}\text { Personal de } \\
\text { nivel superior }\end{array}$ & 0,604 & 0,365 & 0,259 & 0,113 \\
\hline $\begin{array}{l}\text { Presupuesto } \\
\text { económico }\end{array}$ & 0,660 & 0,436 & 0,342 & 0,075 \\
\hline
\end{tabular}

Fuente: Elaboración propia a partir de la Encuesta.

En esta tabla se observa que para el modelo propuesto el coeficiente 0,363 indica que por cada unidad de cambio en MIR se produce un cambio de 0,363 unidades $[36,3 \%]$ en el número de tesis doctorales con la significación del 0,152 $[84,8 \%]$.

El coeficiente 0,365 indica que por cada unidad de cambio en personal de nivel superior se produce un cambio de 0,365 unidades [36,5\%] en el número de tesis doctorales con la significación del $0,113[88,7 \%]$ y el coeficiente 0,436 indica que por cada unidad de cambio en el presupuesto económico se produce un cambio de 0,436 unidades [43,6\%] en el número de tesis doctorales con la significación del 0,075 [92,5\%].

TABLA 7.56. Análisis de Regresión Lineal de número de alumnos de medicina.

\begin{tabular}{|l|c|c|c|c|}
\hline $\begin{array}{l}\text { Variables } \\
\text { predictoras }\end{array}$ & $\begin{array}{c}\mathrm{R} \\
\text { Correlación de } \\
\text { Pearson }\end{array}$ & $\begin{array}{c}\mathrm{R}^{2} \\
\text { Coeficiente de } \\
\text { determinación }\end{array}$ & $\mathrm{R}^{2}$ corregida & $\begin{array}{c}\text { Significación del } \\
\text { cambio en } \mathrm{F}\end{array}$ \\
\hline MIR & 0,685 & 0,470 & 0,337 & 0,133 \\
\hline $\begin{array}{l}\text { Personal de } \\
\text { nivel superior }\end{array}$ & 0,746 & 0,557 & 0,446 & 0,088 \\
\hline $\begin{array}{l}\text { Presupuesto } \\
\text { económico }\end{array}$ & 0,695 & 0,483 & 0,353 & 0,126 \\
\hline
\end{tabular}

Fuente: Elaboración propia a partir de la Encuesta.

En esta tabla se observa que para el modelo propuesto el coeficiente 0,470 indica que por cada unidad de cambio en MIR se produce un cambio de 0,470 unidades [47,0\%] en el número de alumnos de medicina con la significación del 0,133 [86,7\%]. 
El coeficiente 0,557 indica que por cada unidad de cambio en personal de nivel superior se produce un cambio de 0,557 unidades [55,7\%] en el número de alumnos de medicina con la significación del 0,088 [91,2\%] y el coeficiente 0,483 indica que por cada unidad de cambio en el presupuesto económico se produce un cambio de 0,483 unidades [48,3\%] en el número de alumnos de medicina con la significación del 0,126 [87,4\%].

TABLA 7.57. Análisis de Regresión Lineal de otras publicaciones.

\begin{tabular}{|l|c|c|c|c|}
\hline $\begin{array}{l}\text { Variables } \\
\text { predictoras }\end{array}$ & $\begin{array}{c}\mathrm{R} \\
\text { Correlación de } \\
\text { Pearson }\end{array}$ & $\begin{array}{c}\mathrm{R}^{2} \\
\text { Coeficiente de } \\
\text { determinación }\end{array}$ & $\mathrm{R}^{2}$ corregida & $\begin{array}{c}\text { Significación del } \\
\text { cambio en F }\end{array}$ \\
\hline MIR & 0,173 & 0,030 & $-0,164$ & 0,711 \\
\hline $\begin{array}{l}\text { Personal de } \\
\text { nivel superior }\end{array}$ & 0,209 & 0,044 & $-0,116$ & 0,619 \\
\hline $\begin{array}{l}\text { Presupuesto } \\
\text { económico }\end{array}$ & 0,248 & 0,061 & $-0,095$ & 0,554 \\
\hline
\end{tabular}

Fuente: Elaboración propia a partir de la Encuesta.

En esta tabla se observa que para el modelo propuesto el coeficiente 0,030 indica que por cada unidad de cambio en MIR se produce un cambio de 0,030 unidades $[3,0 \%$ en el número de otras publicaciones con la significación del 0,711 [28,9\%]. El coeficiente 0,044 indica que por cada unidad de cambio en personal de nivel superior se produce un cambio de 0,044 unidades $[4,4 \%]$ en el número de otras publicaciones con la significación del $0,619[38,1 \%$ y el coeficiente 0,061 indica que por cada unidad de cambio en el presupuesto económico se produce un cambio de 0,061 unidades $[6,1 \%]$ en el número de otras publicaciones con la significación del $0,061[44,6 \%]$.

Como se puede comprobar los resultados estadísticos muestran unos valores de $\mathrm{R}^{2}$ corregida negativo para los tres casos indicando una relación inversa de otras publicaciones-MIR, otras publicaciones-personal de nivel superior y otras publicaciones-presupuesto económico, por lo tanto la novalidez de la hipótesis.

En otras palabras, el hecho de que los hospitales tengan una mayor plantilla de MIR, de personal de nivel superior y un mayor presupuesto económico no hace prever que produzcan un mayor número de otras publicaciones. 
TABLA 7.58. Análisis de Regresión Lineal de otras publicaciones.

\begin{tabular}{|l|c|c|c|c|}
\hline $\begin{array}{l}\text { Variables } \\
\text { predictoras }\end{array}$ & $\begin{array}{c}\mathrm{R} \\
\text { Correlación de } \\
\text { Pearson }\end{array}$ & $\begin{array}{c}\mathrm{R}^{2} \\
\text { Coeficiente de } \\
\text { determinación }\end{array}$ & $\mathrm{R}^{2}$ corregida & $\begin{array}{c}\text { Significación del } \\
\text { cambio en } \mathrm{F}\end{array}$ \\
\hline $\begin{array}{l}\text { Actividad } \\
\text { científica }\end{array}$ & 0,196 & 0,038 & $-0,122$ & 0,642 \\
\hline
\end{tabular}

Fuente: Elaboración propia a partir de la Encuesta.

En esta tabla se observa que para el modelo propuesto el coeficiente 0,038 indica que por cada unidad de cambio en actividad científica se produce un cambio de 0,038 unidades $[3,8 \%$ en el número de otras publicaciones con la significación del 0,642 [35,8\%].

Como se puede comprobar el resultado estadístico muestra un valor de $\mathrm{R}^{2}$ corregida negativo para este nuevo modelo indicando una relación inversa de otras publicaciones_-actividad científica, por lo tanto la no—validez de la hipótesis.

En otras palabras, el hecho de que los hospitales produzcan un mayor número de actividad científica no hace prever que publiquen un mayor número de otras publicaciones.

TABLA 7.59. Análisis de Regresión Lineal de publicaciones SCI.

\begin{tabular}{|l|c|c|c|c|}
\hline $\begin{array}{l}\text { Variables } \\
\text { predictoras }\end{array}$ & $\begin{array}{c}\mathrm{R} \\
\text { Correlación de } \\
\text { Pearson }\end{array}$ & $\begin{array}{c}\mathrm{R}^{2} \\
\text { Coeficiente de } \\
\text { determinación }\end{array}$ & $\mathrm{R}^{2}$ corregida & $\begin{array}{c}\text { Significación del } \\
\text { cambio en } \mathrm{F}\end{array}$ \\
\hline MIR & 0,687 & 0,472 & 0,297 & 0,200 \\
\hline $\begin{array}{l}\text { Personal de } \\
\text { nivel superior }\end{array}$ & 0,733 & 0,537 & 0,421 & 0,098 \\
\hline $\begin{array}{l}\text { Presupuesto } \\
\text { económico }\end{array}$ & 0,775 & 0,600 & 0,500 & 0,070 \\
\hline
\end{tabular}

Fuente: Elaboración propia a partir de la Encuesta.

En esta tabla se observa que para el modelo propuesto el coeficiente 0,472 indica que por cada unidad de cambio en MIR se produce un cambio de 0,472 unidades $[47,2 \%]$ en el número de publicaciones SCI con la significación del $0,200[80,0 \%]$. El coeficiente 0,537 indica que por cada unidad de cambio en personal de nivel superior se produce un cambio de 0,537 unidades [53,7\%] en el número de publicaciones SCI con la significación del 0,098 [90,2\%] y el coeficiente 0,600 indica que por cada unidad de cambio en el presupuesto económico se 
produce un cambio de 0,600 unidades $[60,0 \%]$ en el número de publicaciones SCI con la significación del 0,070 [93,0\%].

TABLA 7.60. Análisis de Regresión Lineal del factor de impacto de las publicaciones SCI.

\begin{tabular}{|l|c|c|c|c|}
\hline $\begin{array}{l}\text { Variables } \\
\text { predictoras }\end{array}$ & $\begin{array}{c}\mathrm{R} \\
\text { Correlación de } \\
\text { Pearson }\end{array}$ & $\begin{array}{c}\mathrm{R}^{2} \\
\text { Coeficiente de } \\
\text { determinación }\end{array}$ & $\mathrm{R}^{2}$ corregida & $\begin{array}{c}\text { Significación del } \\
\text { cambio en } \mathrm{F}\end{array}$ \\
\hline MIR & 0,338 & 0,114 & $-0,181$ & 0,578 \\
\hline $\begin{array}{l}\text { Personal de } \\
\text { nivel superior }\end{array}$ & 0,313 & 0,098 & $-0,127$ & 0,545 \\
\hline $\begin{array}{l}\text { Presupuesto } \\
\text { económico }\end{array}$ & 0,367 & 0,135 & $-0,082$ & 0,474 \\
\hline
\end{tabular}

Fuente: Elaboración propia a partir de la Encuesta.

En esta tabla se observa que para el modelo propuesto el coeficiente 0,114 indica que por cada unidad de cambio en MIR se produce un cambio de 0,114 unidades $[11,4 \%]$ en el factor de impacto de las publicaciones SCI con la significación del 0,578 [42,2\%]. El coeficiente 0,098 indica que por cada unidad de cambio en personal de nivel superior se produce un cambio de 0,098 unidades $[9,8 \%]$ en el factor de impacto de las publicaciones SCI con la significación del $0,545[45,5 \%$ y el coeficiente 0,135 indica que por cada unidad de cambio en el presupuesto económico se produce un cambio de 0,135 unidades $[13,5 \%]$ en el factor de impacto de las publicaciones SCI con la significación del 0,474 [52,6\%].

Como se puede comprobar los resultados estadísticos muestran unos valores de $\mathrm{R}^{2}$ corregida negativo para los tres casos indicando una relación inversa al factor de impacto-MIR, factor de impacto-personal de nivel superior y factor de impacto-presupuesto económico, por lo tanto la novalidez de la hipótesis.

En otras palabras, el hecho de que los hospitales tengan una mayor plantilla de MIR, de personal de nivel superior y un mayor presupuesto económico no hace prever que el factor de impacto de las publicaciones SCI sea mayor. 
TABLA 7.61. Análisis de Regresión Lineal del factor de impacto de las publicaciones SCI.

\begin{tabular}{|l|c|c|c|c|}
\hline $\begin{array}{l}\text { Variables } \\
\text { predictoras }\end{array}$ & $\begin{array}{c}\mathrm{R} \\
\text { Correlación de } \\
\text { Pearson }\end{array}$ & $\begin{array}{c}\mathrm{R}^{2} \\
\text { Coeficiente de } \\
\text { determinación }\end{array}$ & $\mathrm{R}^{2}$ corregida & $\begin{array}{c}\text { Significación del } \\
\text { cambio en } \mathrm{F}\end{array}$ \\
\hline $\begin{array}{l}\text { Publicaciones } \\
\text { SCI }\end{array}$ & 0,459 & 0,210 & 0,013 & 0,360 \\
\hline
\end{tabular}

Fuente: Elaboración propia a partir de la Encuesta.

En esta tabla se observa que para el modelo propuesto el coeficiente 0,210 indica que por cada unidad de cambio en las publicaciones SCI se produce un cambio de 0,210 unidades [21,0\%] en el factor de impacto de las publicaciones SCI con la significación del 0,360 [64,0\%].

Como se puede comprobar el resultado estadístico muestra un valor de $\mathrm{R}^{2}$ corregida muy próximo a cero por lo que se puede concluir que existe poca relación del número de publicaciones SCI con el factor de impacto de esas publicaciones y también que la significación del modelo alrededor del $60 \%$ es baja.

En otras palabras, un mayor número de publicaciones SCI no hace prever un mayor factor de impacto para esas publicaciones.

\subsubsection{INTERPRETACIÓN DE LOS RESULTADOS OBTENIDOS}

El objetivo de esta cuarta fase de análisis ha sido el de analizar la aportación que hacen al SI—SSPC los hospitales de alta tecnología.

Los resultados de las diferentes tablas presentan una tendencia común no confirmando la primera hipótesis de partida.

Respecto a la dispersión de los valores de las variables estudiadas, con excepción de tesis doctorales [Clínic con 38,9\%] y proyectos de investigación [Vall d'Hebron con 57,8\%], todas las variables presentan una desviación típica inferior a la media demostrando que existe una gran homogeneidad en las actividades que realizan los hospitales del Grupo 4.

La tabla 7.62 muestra un resumen de las variables estudiadas. 
TABLA 7.62. Resultados de las variables del estudio de la Fase 4.

\begin{tabular}{|c|c|c|c|c|}
\hline $\begin{array}{|cc|}\text { Variable } & \text { Hospital } \\
& \end{array}$ & CSUVH & $\mathrm{HC}$ & CSUB & HSCSP \\
\hline $\begin{array}{l}\text { > presupuesto } \\
\text { económico }\end{array}$ & $\mathbf{x}$ & & & \\
\hline $\begin{array}{l}>\text { plantilla personal de } \\
\text { nivel superior }\end{array}$ & $\mathbf{x}$ & & & \\
\hline $\begin{array}{l}>n^{0} \text { actividad } \\
\text { científica }\end{array}$ & $\mathbf{X}$ & & & \\
\hline$>n^{0}$ de MIR & $\bar{x}$ & & & \\
\hline$>n^{0}$ de camas & $\bar{x}$ & & & \\
\hline $\begin{array}{l}>n^{\circ} \text { proyectos de } \\
\text { investigación }\end{array}$ & $\mathbf{x}$ & & & \\
\hline $\begin{array}{l}>n^{0} \text { alumnos de } \\
\text { medicina }\end{array}$ & $\bar{x}$ & & & \\
\hline$>n^{0}$ publicaciones $\mathrm{SCI}$ & & $\mathbf{x}$ & & \\
\hline $\begin{array}{l}>n^{0} \text { otras } \\
\text { publicaciones }\end{array}$ & & $\mathbf{x}$ & & \\
\hline$>n^{0}$ tesis doctorales & & $\mathbf{x}$ & & \\
\hline$>n^{\circ}$ de trasplantes & & $\mathbf{x}$ & & \\
\hline $\begin{array}{l}\text { > factor de impacto de } \\
\text { las publicaciones SCI }\end{array}$ & & & $\mathbf{x}$ & \\
\hline$>n^{\circ}$ ensayos clínicos & & & & $x$ \\
\hline
\end{tabular}

Fuente: Elaboración propia a partir de la Encuesta. 
TABLA 7.63. Resultado de los índices del estudio de la Fase 4.

\begin{tabular}{|c|c|c|c|c|c|c|}
\hline Variable ${ }^{\text {Hospital }}$ & $\mathrm{HC}$ & HSCSP & ICO & FP & HUGTIP & HSJD \\
\hline$>$ PSCI/PNS & & & $\mathbf{x}$ & & & \\
\hline$>$ OP/PNS & & & & $\bar{x}$ & & \\
\hline > PSCI/presupuesto & & & $x$ & & & \\
\hline$>$ OP/presupuesto & & & $\mathbf{x}$ & & & \\
\hline$>A C / P N S$ & & & $\mathbf{x}$ & & & \\
\hline$>$ TD/PNS & $\mathbf{x}$ & & & & & \\
\hline$>$ AC/presupuesto & & & $\mathbf{x}$ & & & \\
\hline > TD/presupuesto & $\bar{x}$ & & & & & \\
\hline$>$ TR/PNS & & & & $\mathrm{x}$ & & \\
\hline$>\mathrm{CA} / \mathrm{PNS}$ & & & & $\mathbf{X}$ & & \\
\hline$>$ TR/presupuesto & & & & & $\bar{x}$ & \\
\hline$>$ CA/presupuesto & & & & & & $x$ \\
\hline$>$ PI/PNS & & & $x$ & & & \\
\hline$>$ EC/PNS & & & $\mathbf{x}$ & & & \\
\hline$>$ PI/presupuesto & & & $\mathbf{x}$ & & & \\
\hline$>\mathrm{EC} /$ presupuesto & & $\mathbf{x}$ & & & & \\
\hline$>$ MIR/PNS & & & & & $x$ & \\
\hline$>$ AM/PNS & & & & & & $\bar{x}$ \\
\hline > MIR/presupuesto & & & & & $\bar{x}$ & \\
\hline$>$ AM/presupuesto & & & & & & $\bar{x}$ \\
\hline
\end{tabular}

Fuente: Elaboración propia a partir de la Encuesta.

El análisis de la tabla 7.63 permite averiguar que corresponde al ICO el 40\% [8 de 20] de los índices estudiados, a la Fundació Puigvert el 15\% [3 de 20], al HUGTiP el 15\% [3 de 20], al HSJD el 15\% [3 de 20], al Clínic el 10\% [2 de 20] $y$ al HSCSP el 5\% [1 de 20].

Este estudio ha tenido como objetivo ver que hospitales dedican más medios a las actividades de investigación y docencia del sistema. Queda claro que los mayores hospitales que tienen las mayores producciones en números absolutos no son los que dedican más medio para la consecución de estas actividades.

Con relación a la segunda y tercera hipótesis planteada, la tabla 7.64 muestra que excluyendo las tres variables señaladas, donde la $\mathrm{R}^{2}$ corregida es negativa indicando la existencia de una relación inversa a la planteada, por lo tanto 
invalidando las hipótesis, las demás validan las hipótesis con una significación que varía del 0,200 al 0,000 [80,0 al 100,0\%], por lo tanto a un mayor presupuesto económico y a una mayor plantilla de personal de nivel superior se hace prever una mayor actividad de los hospitales de alta tecnología con relación a las variables estudiadas.

TABLA 7.64. Resultados de la Regresión Lineal.

\begin{tabular}{|l|c|c|c|c|c|c|c|c|c|c|c|c|}
\hline \multicolumn{1}{|c}{$\begin{array}{r}\text { Variable } \\
\text { dependiente }\end{array}$} & \multicolumn{5}{|c|}{ MIR } & \multicolumn{5}{c|}{$\begin{array}{c}\text { Personal de nivel } \\
\text { Superior }\end{array}$} & \multicolumn{5}{c|}{ Presupuesto } \\
\hline $\begin{array}{l}\text { Variable } \\
\text { independiente }\end{array}$ & $\mathrm{R}^{2}$ & $\begin{array}{c}\mathrm{R}^{2} \\
\%\end{array}$ & $\mathrm{~F}$ & $\begin{array}{c}\mathrm{F} \\
\%\end{array}$ & $\mathrm{R}^{2}$ & $\begin{array}{c}\mathrm{R}^{2} \\
\%\end{array}$ & $\mathrm{~F}$ & $\begin{array}{c}\mathrm{F} \\
\%\end{array}$ & $\mathrm{R}^{2}$ & $\begin{array}{c}\mathrm{R}^{2} \\
\%\end{array}$ & $\mathrm{~F}$ & $\begin{array}{c}\mathrm{F} \\
\%\end{array}$ \\
\hline $\begin{array}{l}\text { Actividad } \\
\text { científica }\end{array}$ & 0,556 & 55,6 & 0,054 & 94,6 & 0,345 & 34,5 & 0,126 & 87,4 & 0,324 & 32,4 & 0,141 & 85,9 \\
\hline Camas & 0,972 & 97,2 & 0,000 & 100,0 & 0,957 & 95,7 & 0,000 & 100,0 & 0,976 & 97,6 & 0,000 & 100,0 \\
\hline $\begin{array}{l}\text { Ensayos } \\
\text { clínicos }\end{array}$ & 0,538 & 53,8 & 0,061 & 93,9 & 0,446 & 44,6 & 0,070 & 93,0 & 0,557 & 55,7 & 0,033 & 96,7 \\
\hline $\begin{array}{l}\text { Proyectos de } \\
\text { investigación }\end{array}$ & 0,743 & 74,3 & 0,013 & 98,7 & 0,722 & 72,2 & 0,008 & 99,9 & 0,682 & 68,2 & 0,012 & 98,8 \\
\hline $\begin{array}{l}\text { Trasplantes } \\
\text { Tesis } \\
\text { doctorales }\end{array}$ & 0,163 & 16,3 & 0,368 & 63,2 & 0,084 & 8,4 & 0,527 & 47,3 & 0,137 & 13,7 & 0,414 & 58,6 \\
\hline $\begin{array}{l}\text { Alumnos } \\
\text { medicina }\end{array}$ & 0,470 & 47,0 & 0,133 & 86,7 & 0,557 & 55,7 & 0,088 & 91,2 & 0,483 & 48,3 & 0,126 & 87,4 \\
\hline $\begin{array}{l}\text { Otras } \\
\text { publicaciones }\end{array}$ & 0,030 & 3,0 & 0,711 & 28,9 & 0,044 & 4,4 & 0,619 & 38,1 & 0,061 & 6,1 & 0,554 & 44,6 \\
\hline $\begin{array}{l}\text { Publicaciones } \\
\text { SCI }\end{array}$ & 0,472 & 47,2 & 0,200 & 80,0 & 0,537 & 53,7 & 0,098 & 90,2 & 0,600 & 60,0 & 0,070 & 93,0 \\
\hline $\begin{array}{l}\text { Factor } \\
\text { impacto SCI }\end{array}$ & 0,114 & 11,4 & 0,578 & 42,2 & 0,098 & 9,8 & 0,545 & 45,5 & 0,135 & 13,5 & 0,474 & 52,6 \\
\hline
\end{tabular}

Fuente: Elaboración propia a partir de la Encuesta.

Otras observaciones que pueden detectarse son la máxima diferencia entre la comparación de los estadísticos de las variables estudiadas comunes a todos los actores, donde más de una vez la media de actividad científica y otras publicaciones de los hospitales es mayor que la media de todos los actores y la desviación típica de los hospitales es menor que la media y menor que la desviación típica de todos los actores demostrando una gran homogeneidad global de los hospitales en relación con todos los actores.

En conclusión, tal como se desprende del desarrollo teórico hecho en este trabajo, los hospitales de alta tecnología son los actores que más aportan al sistema tanto en actividad científica y otras publicaciones como en publicaciones SCI, docencia y demás variables específicas estudiadas y, por lo tanto, están 
ubicados en los polos científico y tecnológico del SI-SSPC con gran diferencia en relación con los demás actores estudiados del sistema.

\subsection{FASE 5. ANÁLISIS DE LOS DATOS CUALITATIVOS DE LA ENCUESTA HECHA A LOS ACTORES DEL SI-SSPC}

Los objetivos a contrastar en esta fase son los siguientes:

5.1. Determinación de la intensidad y el tipo de relación que mantienen los actores del SI-SSPC.

5.2. Determinación de la incidencia y situación actual de los recursos generadores de éxito [descritos en el capítulo 3 del estudio] en el SI-SSPC.

5.3. Determinación de otros factores responsables de la actividad científica-innovadora de los actores del SI-SSPC.

5.4. Establecer una tipología que permita definir el papel de los actores en el SI-SSPC.

En esta fase se ha analizado las preguntas de la parte 4 de la encuesta — la encuesta hecha a los actores del SI-SSPC se encuentra en el anexo 3- que recoge los datos sobre las relaciones de enlace y cooperación que mantienen los actores del SI-SSPC entre sí y su intensidad.

\subsubsection{RESULTADO Y DESCRIPCIÓN DE LAS TABLAS}

Los encuestados consideran que, en general, existe un número medio-bajo de relaciones de cooperación entre los actores del SI-SSPC, asimismo opinan que por parte del comprador-financiador [SCS] se debería fomentar la creación de medios para que se diera esas relaciones en el sistema y sancionar las norelaciones que mantienen algunos de los actores sea por competencia a favor de la creatividad en las tareas de investigación científica y producción de innovaciones o por la competencia que mantienen por los subsidios que aporta el SCS a los actores del sistema. La tabla 7.65 resume la intensidad y las relaciones que existen en el sistema. 
TABLA 7.65. Relaciones existentes entre los actores del SI-SSPC.

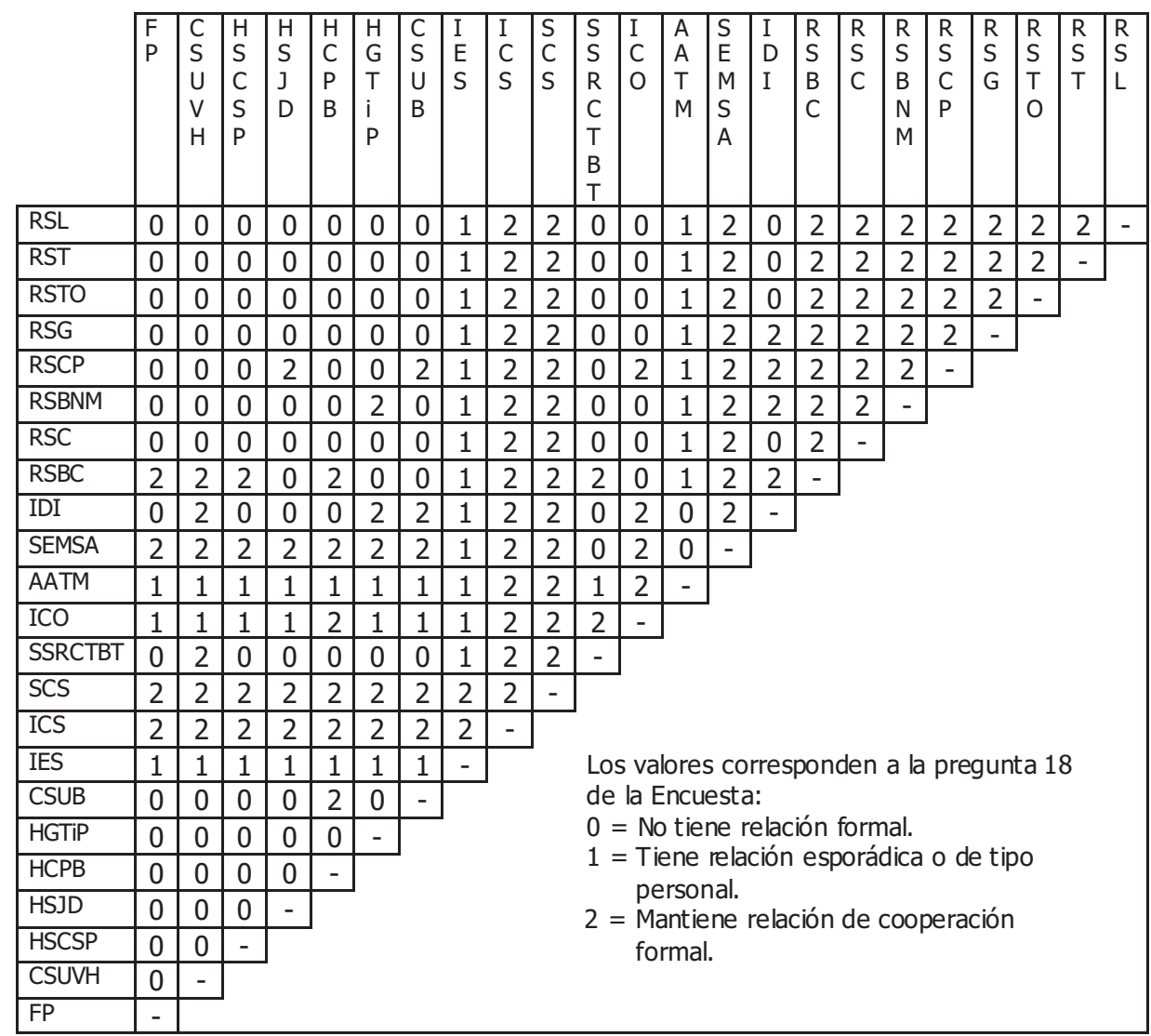

Fuente: Encuesta, pregunta 18. Número de respuestas: 23.

En esta tabla se observa que las 263 posibles relaciones entre los actores del SI—SSPC se configuran de la siguiente manera [clasificación subjetiva según la Encuesta, pregunta 18]:

- El 42,2\% [111/263] de esas relaciones son de tipo 0 [no existe relación formal] entre los actores del SI-SSPC. Se observa que estas relaciones están concentradas en dos grandes grupos que son por una parte las regiones sanitarias y los hospitales de alta tecnología que no tienen relación entre sí. Asimismo, este tipo de relación aparece en algunas de las empresas públicas del SCS que no mantienen relaciones con los demás actores que están fuera de su entorno hospitalario y que son básicamente el IDI, ICO y SSRCTBT. 
- El 16,0\% [42/263] de esas relaciones son de tipo 1 [tiene relación esporádica o de tipo personal] entre los actores del SI—SSPC. Se observa que estas relaciones se establecen con dos actores en concreto, la AATM y el IES. Estos actores tienen en el sistema, hoy, un papel poco definido, el IES es contactado por los demás actores cuando estés necesitan una acreditación de sus programas de entrenamiento [cursos, seminarios, etc.] para poder recibir las subvenciones del SCS y la AATM es el actor que tiene el menor presupuesto y su actividad es cuestionada por la mayoría de los entrevistados.

- El 41,8\% [110/263] de estas relaciones son de tipo 2 [mantiene relación de cooperación formal]. Nuevamente se observa que estas relaciones están concentradas en tres de los actores y que son las regiones sanitarias [relaciones que mantienen entre ellas] el SCS [relaciones que mantienen todos los actores con el planificador-comprador y proveedor del SSPC] y el ICS [mayor proveedor del SSPC].

En la siguiente tabla se resume las relaciones existentes en el SI-SSPC que según la Encuesta [clasificación subjetiva según la Encuesta, pregunta 18] se dividen en tres tipos 0,1 y 2 , suman un total posible de 263 relaciones y quedan clasificadas de la siguiente forma: relación tipo $0=42,2 \%$ [111/263], relación tipo $1=16,0 \%[42 / 263]$ y relación tipo $2=41,8 \%$ [110/263].

TABLA 7.66. Resumen de las relaciones del SI-SSPC.

\begin{tabular}{|l|c|c|}
\hline Tipo de relación & Número & $\%$ \\
\hline Tipo 0 & 111 & 42,2 \\
\hline$\overline{\text { Tipo } 1}$ & 42 & 16,0 \\
\hline Tipo 2 & 110 & 41,8 \\
\hline Total & $\mathbf{2 6 3}$ & $\mathbf{1 0 0 , 0}$ \\
\hline
\end{tabular}

Fuente: Encuesta, pregunta 18. Número de respuestas: 23.

En la siguiente tabla se tabula las respuestas de la pregunta número 20 de la Encuesta que intenta determinar la situación o incidencia de los factores de éxito [descritos en el capítulo tres del estudio] en el SI-SSPC.

En esta tabla se observa [clasificación subjetiva según la Encuesta, pregunta 20] la unanimidad de los encuestados a la hora de contestar sobre el factor Flexibilidad del sector y/o de los actores. 
En la opinión de los entrevistados no existe ningún tipo de flexibilidad en el sistema, los actores que tienen personal sanitario en régimen estatutario son los más incisivos en recalcar que este tipo de Recursos Humanos imposibilita cualquier tentativa de flexibilización del trabajo o de la propia institución.

También en relación con la gestión de la innovación y la red cooperativa los encuestados, en su mayoría, coinciden en afirmar que no existe gestión de la innovación y red cooperativa o que estos factores tienen una baja incidencia en el SI-SSPC.

La tabla 7.67 recoge las respuestas de la pregunta 20 de la Encuesta en la opinión de los entrevistados y resume la incidencia de los factores de éxito en el SI-SSPC. 
TABLA 7.67. Situación/incidencia de los factores de éxito en el SI-SSPC.

\begin{tabular}{|c|c|c|c|c|c|}
\hline $\begin{array}{l}\text { Factor de } \\
\text { éxito } \\
\text { Número de } \\
\text { la entrevista } \\
\end{array}$ & $\begin{array}{l}\text { Disponibilidad } \\
\text { de } \\
\text { información }\end{array}$ & $\begin{array}{c}\text { Conocimientos } \\
\text { acumulados }\end{array}$ & $\begin{array}{c}\text { Red } \\
\text { cooperativa }\end{array}$ & Flexibilidad & $\begin{array}{l}\text { Gestión de la } \\
\text { innovación }\end{array}$ \\
\hline 1 & 2 & 3 & 2 & 0 & 2 \\
\hline 3 & 2 & 3 & 2 & 0 & 2 \\
\hline 5 & 2 & 2 & 1 & 1 & 1 \\
\hline 6 & 2 & 2 & 1 & 0 & 0 \\
\hline 7 & 2 & 3 & 1 & 0 & 1 \\
\hline 8 & 1 & 2 & 0 & 0 & 0 \\
\hline 10 & 1 & 2 & 0 & 0 & 0 \\
\hline 11 & 1 & 3 & 1 & 0 & 0 \\
\hline 12 & 2 & 2 & 1 & 0 & 1 \\
\hline 14 & 2 & 2 & 1 & 1 & 2 \\
\hline 15 & 3 & 3 & 2 & 2 & 1 \\
\hline 16 & 1 & 3 & 0 & 0 & 0 \\
\hline 17 & 1 & 2 & 0 & 0 & 0 \\
\hline 18 & 2 & 2 & 1 & 0 & 0 \\
\hline 19 & 2 & 2 & 1 & 0 & 1 \\
\hline 20 & 1 & 3 & 0 & 0 & 0 \\
\hline 21 & 1 & 2 & 0 & 0 & 0 \\
\hline 22 & 2 & 2 & 2 & 1 & 2 \\
\hline 23 & 3 & 3 & 0 & 0 & 2 \\
\hline 24 & 2 & 3 & 2 & 1 & 2 \\
\hline 25 & 2 & 2 & 2 & 0 & 1 \\
\hline 26 & 2 & 2 & 2 & 0 & 1 \\
\hline 28 & 3 & 3 & 2 & 2 & 2 \\
\hline 29 & 1 & 2 & 0 & 0 & 0 \\
\hline 30 & 1 & 3 & 1 & 0 & 0 \\
\hline 31 & 3 & 3 & 1 & 0 & 1 \\
\hline 32 & 3 & 3 & 1 & 0 & 1 \\
\hline 33 & 1 & 3 & 0 & 0 & 0 \\
\hline 34 & 3 & 3 & 0 & 0 & 0 \\
\hline 35 & 2 & 3 & 0 & 0 & 0 \\
\hline 36 & 3 & 3 & 2 & 2 & 2 \\
\hline 37 & 2 & 2 & 1 & 1 & 1 \\
\hline 38 & 2 & 2 & 0 & 0 & 0 \\
\hline 39 & 3 & 3 & 2 & 0 & 2 \\
\hline 40 & 2 & 2 & 1 & 0 & 0 \\
\hline 41 & 1 & 3 & 1 & 0 & 1 \\
\hline 42 & 1 & 2 & 0 & 0 & 0 \\
\hline 43 & 3 & 3 & 0 & 0 & 0 \\
\hline 44 & 2 & 2 & 0 & 0 & 0 \\
\hline 47 & 2 & 2 & 1 & 1 & 1 \\
\hline 49 & 1 & 2 & 1 & 0 & 0 \\
\hline 51 & 1 & 3 & 0 & 0 & 0 \\
\hline \multicolumn{6}{|c|}{$\begin{array}{l}\text { Situación o incidencia del factor de éxito en su entorno: } \\
0=\text { no existe \# } 1 \text { = baja \# } 2 \text { = media \# } 3 \text { = alta } \\
\text { Número de la entrevista: orden de la lista alfabética de las entrevistas, } \\
\text { capítulo } 3 \text { del estudio. }\end{array}$} \\
\hline
\end{tabular}

Fuente: Encuesta, pregunta 20. Número de respuestas: 23. 
En esta tabla se observa que los factores de éxito del SI-SSPC se configuran de la siguiente forma [clasificación subjetiva según la Encuesta, pregunta 20]:

- Factor de éxito disponibilidad de información. De los 42 entrevistados $21,5 \%$ [9/42] considera que este factor tiene una incidencia de tipo 3; $45,2 \%$ [19/42] considera que este factor tiene una incidencia de tipo 2 y $33,3 \%$ [14/42] considera que este factor tiene una incidencia de tipo 1. Como se puede comprobar los encuestados son unánimes en afirmar que este factor de éxito tiene alguna incidencia en el sistema pues ninguno de ellos contesto que este factor no existiera en el SISSPC, incidencia de tipo 0.

En la opinión de los entrevistados lo que falta en el sistema son unos estándares para que la información o una parte de la información sea homogénea, todos los actores generan una gran cantidad de datos y de información que no puede ser comparada con la de otros actores por la falta de esos estándares mínimos. También como ya comentamos existe la Central de Balanços del SCS que anualmente recoge unas informaciones y hace un informe que esta accesible solamente al gerente de cada institución. Esta información esta estandarizada pero como es información privilegiada nosotros no tuvimos acceso a ella para agregarla y analizarla en este estudio.

- Factor de éxito conocimientos acumulados. De los 42 entrevistados $50,0 \%$ [21/42] considera que este factor tiene una incidencia de tipo 3 y $50,0 \%$ [21/42] considera que este factor tiene una incidencia de tipo 2. Como se puede comprobar, nuevamente, los encuestados son unánimes en afirmar que este factor de éxito tiene una incidencia considerable en el SI-SSPC.

La historia hospitalaria catalana es rica y esta tradición aporta a los actores unos conocimientos acumulados importantes. El hospital de la Santa Creu i Sant Pau es una prueba de esto, con más de 600 años de existencia es hoy uno de los 10 hospitales de alta tecnología del SI-SSPC.

- Factor de éxito red cooperativa. De los 42 entrevistados 23,8\% [10/42] considera que este factor tiene una incidencia de tipo 2; 38,1\% [16/42] de los entrevistados considera que este factor tiene una incidencia de tipo 1 y 38,1\% [16/42] considera que este factor tiene una incidencia de tipo 0 . Como se puede comprobar más de la mitad de los encuestados tienen la opinión de que este factor no existe o si existe que tiene una 
incidencia muy baja en el SI—SSPC. También es importante resaltar que ninguno de los entrevistados consideró que este factor tuviera una incidencia de tipo 3 en el SI-SSPC.

En la opinión de los entrevistados existe más competencia que posible red de cooperación entre los actores del SI-SSPC y que esa competencia tiene mucho que ver con los subsidios que tiene la estructura del SI-SSPC. Los entrevistados opinan que esta competencia por los subsidios desaparecerá con la desaparición de ese «vicio» creado en el seno del sistema y es cuando puede surgir, dependiendo de la política adoptada por el SCS, una red de cooperación entre todos los actores y donde, en teoría, todos serian beneficiados.

- Factor de éxito flexibilidad. De los 42 entrevistados 7,1\% [3/42] considera que este factor tiene una incidencia de tipo $2 ; 14,3 \%$ [6/42] considera que este factor tiene una incidencia de tipo 1 y $78,6 \%$ [33/42] considera que este factor tiene una incidencia de tipo 0 . Como se puede comprobar 33 de los entrevistados tienen la opinión de que no existe flexibilidad alguna en el SI-SSPC.

Los entrevistados consideran que el causador de la no-existencia de este factor de éxito en el sistema es la gran cantidad de personal sanitario en régimen estatutario que imposibilita cualquier iniciativa en este sentido y que cualquier medida política en esta dirección podría causar alarma social [por citar algunas medidas, estas podrían ser de tipo jubilación anticipada, creación de más empresas públicas con personal sanitario a régimen laboral, etc.].

- Factor de éxito gestión de la innovación. De los 42 entrevistados $21,5 \%$ [9/42] considera que este factor tiene una incidencia de tipo 2 ; $28,5 \%$ [12/42] considera que este factor tiene una incidencia de tipo 1 y $50,0 \%$ [21/42] considera que este factor tiene una incidencia de tipo 0. Como se puede comprobar la mitad de los entrevistados consideran que no existe una gestión de la innovación y de la I+D y de las nuevas tecnologías en el SI-SSPC.

En la opinión de los entrevistados, cuando se habla de innovación, de nuevas tecnologías, de nuevos aparatos, etc., estas demandas parten de los jefes de equipos, ningún de los actores entrevistados tiene en su estructura funcional un sector o una persona que trate de estos temas de manera global para toda la entidad. En los presupuestos anuales, del actor, se destina alguna partida para estos temas siempre 
y cuando exista una demanda por parte de alguno de los jefes de equipo, en lo caso de los hospitales de alta tecnología, o de algún jefe de sector o de área en los demás casos.

La siguiente tabla contiene un resumen numérico de los factores de éxito abordados hasta el momento.

TABLA 7.68. Resumen de los factores de éxito del SI-SSPC.

\begin{tabular}{|c|c|c|c|}
\hline Factor de éxito & Tipo de incidencia & $\begin{array}{l}\text { Número de } \\
\text { respuestas }\end{array}$ & $\%$ \\
\hline \multirow{4}{*}{\begin{tabular}{|l} 
Disponibilidad de \\
información
\end{tabular}} & 0 & 0 & 0,0 \\
\hline & 1 & 14 & 33,3 \\
\hline & 2 & 19 & 45,2 \\
\hline & 3 & 9 & 21,5 \\
\hline \begin{tabular}{|l|} 
Total \\
\end{tabular} & - & 42 & 100,0 \\
\hline \multirow{4}{*}{$\begin{array}{l}\text { Conocimientos } \\
\text { acumulados }\end{array}$} & 0 & 0 & 0,0 \\
\hline & 1 & 0 & 0,0 \\
\hline & 2 & 21 & 50,0 \\
\hline & 3 & 21 & 50,0 \\
\hline Total & - & 42 & 100,0 \\
\hline \multirow{4}{*}{ Red cooperativa } & 0 & 16 & 38,1 \\
\hline & 1 & 16 & 38,1 \\
\hline & 2 & 10 & 23,8 \\
\hline & 3 & 0 & 0,0 \\
\hline Total & - & 42 & 100,0 \\
\hline \multirow{4}{*}{ Flexibilidad } & $\overline{c 0}$ & 33 & 78,6 \\
\hline & 1 & 6 & 14,3 \\
\hline & 2 & 3 & 7,1 \\
\hline & 3 & 0 & 0,0 \\
\hline Total & - & 42 & 100,0 \\
\hline \multirow{4}{*}{$\begin{array}{l}\text { Gestión de la } \\
\text { innovación }\end{array}$} & 0 & 21 & 50,0 \\
\hline & 1 & 12 & 28,5 \\
\hline & 2 & 9 & 21,5 \\
\hline & 3 & 0 & 0,0 \\
\hline Total & - & 42 & 100,0 \\
\hline
\end{tabular}

Fuente: Encuesta, pregunta 20. Número de respuestas: 42.

En relación con a la pregunta 19 de la Encuesta la respuesta fue que la mayoría de los actores del SI-SSPC mantiene algún tipo de relación de colaboración o convenio internacional. De los 23 encuestados 60,9\% [14/23] mantienen alguna relación con otros actores de fuera del SI-SSPC, que en su mayoría son convenios de colaboración internacional, sea con la OMS, proyectos europeos o colaboración con el tercero mundo. 
En relación con a la pregunta 21 de la Encuesta los entrevistados consideran que existe un hueco en relación con la información del sistema hacia el usuario, asimismo, opinan que deberían acelerarse el proceso de implantación de la tarjeta de identificación magnética que posibilitará crear una base de datos con el historial clínico de los pacientes, que no existe una red informática común en el sistema que permita a todo momento poderse acceder desde cualquier centro sanitario para consultar, entre otros, la historia clínica del paciente. Estas líneas propuestas ya están recogidas en el documento «Catalunya en Xarxa: Pla Estratègic per la Societat de la Informació» publicado por el Comissionat per a la Societat de la Informació en abril de 1999 y que en el capítulo 02.6 Sanitat i Qualitat de Vida propone lo siguiente:

«Catalunya en Xarxa persigue mejorar la calidad de la atención a los pacientes por medio del uso de las Tecnologías de la Sociedad de la Información y la incorporación a las rutinas sanitarias de la digitalización de los diferentes procesos, como puede ser la historia clínica, la calidad clínica asociada a la calidad de gestión y los sistemas de gestión globales».

«El nuevo paradigma de las Salud se fundamenta en una Medicina basada en la evidencia, en la auto-información del usuario, la sostenibilidad, la eficacia y la permeabilización de los profesionales en las nuevas tecnologías y en el cambio».

«El objetivo de la aplicación de las iniciativas propuestas es conseguir un cambio en el papel de los diferentes agentes y el conocimiento de estos agentes. El enfermo ha estado hasta ahora una suma de informaciones dispersas y compartimentadas, mientras que el conocimiento médico y sanitario del enfermo en el futuro será global y trasparente, y permitirá a todos los agentes compartir diagnósticos sobre los diferentes registros del enfermo, cosa que ha de repercutir en un mejor diagnóstico y tratamiento, y en una mejor calidad del servicio para el enfermo».

«La intercomunicación telemática entre los diferentes agentes sanitarios exige un cambio de modalidad en la comunicación, una comunicación ciudadano-servicio diferente a la de ahora, a partir de la tarjeta sanitaria, que pasará de ser una tarjeta con datos meramente administrativos a ser una tarjeta de acceso a la historia clínica. Esta línea estratégica conseguirá, fundamentalmente, la Intranet global sociosanitaria de Catalunya». 
«Las iniciativas que darán forma a esta línea de acción son las siguientes:

- La Intranet Sanitaria.

- La creación de una Agencia de Información Sanitaria.

- La Tarjeta electrónica sanitaria y la historia clínica digital.

- La historia clínica digital.

- Formación y reciclaje en Tecnologías de la Información para los agentes sanitarios».

Como se puede comprobar la opinión le los encuestados no difiere mucho de las líneas estratégicas del documento Catalunya en Xarxa, asimismo, este documento es desconocido por la casi totalidad de los actores entrevistados, donde se percibe que no existe unos canales de información y comunicación o las relaciones entre los actores.

En relación con a la pregunta 17 de la Encuesta, 100\% [23/23] de los entrevistados consideran que el éxito en la producción científica global del actor [cantidad y calidad de la investigación científica, publicación de artículos inéditos o publicaciones SCI, el factor de impacto de esas publicaciones, publicaciones de libros, tesis doctorales, proyectos de investigación, ensayos clínicos, etc.] depende fundamentalmente de los jefes de equipos —en el caso de los hospitales de alta tecnología-, de los directores —en el caso de las empresas públicas - y de los gerentes —en el caso de las regiones sanitarias-. La persona que ocupa uno de estos puestos de trabajo es la que tiene la condición de impulsar o frenar la producción científica global del actor y esta condición depende básicamente del carácter innovador y dinámico de esa persona. Como se puede comprobar en las anteriores fases de análisis del trabajo empírico existe una diferencia importante cuanto a la producción científica global de los actores dentro de un mismo grupo.

En relación con la pregunta 21 de la Encuesta, los entrevistados consideran que, en general, la LOSC no ha sido completamente implantada en Catalunya. La ley tiene unos artículos por cumplir y lo primero que debería hacer el gobierno es decidir si se sigue o si se modifica la ley para que la realidad diaria del sistema no se vea a margen de ésta [por citar algunos ejemplos de pendencia de la ley, la reforma de la asistencia primaria que estaba prevista para terminar en 1996 todavía no ha sido finalizada, la separación de funciones de planificación-compra de las de provisión de servicios sanitarios no es una realidad en el sistema, el SCS como planificador comprador único es a la vez proveedor del sistema, etc.]. 
Por otra parte, en la entrevistas que mantuvimos con los altos cargos del DSSS, del SCS, del ICS y con el Secretario de Gobierno de la Generalitat y de Relaciones con el Parlamet, estos son unánimes en afirmar que cualquier acción en este sentido, de modificación de la ley, tiene un alto coste político, que no existe un consenso en el Parlamento de Catalunya sobre este asunto y que el gobierno no tiene la percepción de que el sistema funcione a margen de la ley.

En la entrevista con el Dr. Josep Maria Via i Redons, Secretario de Gobierno y mentor de la LOSC, este nos hablaba que la LOSC en su momento fue una ley innovadora, que consiguió aglutinar todos los sectores del entorno sanitario catalán y siguiendo las directrices de la LGS organizó lo que hoy se conoce internacionalmente como «Modelo sanitario catalán» que se exporta a varios países de Sudamérica y leste de Europa.

También nos comentaba el Dr. Via que el modelo sanitario catalán no es perfecto y que tiene algunos puntos donde se puede mejorar mucho, pero que esto cuesta dinero y que este dinero no se consigue, fácilmente, hacer llegar en el presupuesto anual para el sector sanitario, que el camino es largo y que día a día se trabaja para mejorar esos punto. Él comentó que esto es verdadero en el sentido de que nunca había visto manifestaciones y acampadas en la plaza Sant Jaume por motivos del mal funcionamiento del sistema, listas de espera, reforma de la primaria, etc., y que la plaza es un termómetro de la sociedad catalana, y que quien habla de listas de espera, etc., es por que no tiene más que hablar de un sistema muy bueno y que mejora día a día.

Finalmente en relación con la pregunta 23 de la Encuesta los entrevistados tienen una opinión muy diversa, 33,3\% [14/42] de los encuestados opinan que si a la pregunta de la viabilidad de la exportación hacia otros países del modelo sanitario catalán, 23,8\% [10/42] de los encuestados opinan que no a la pregunta 23, que el modelo sanitario catalán es una realidad por la tradición histórica de la sociedad civil de Catalunya y que es muy difícil encontrar en el tercero mundo un país con características semejantes a la de Catalunya y 42,9\% [18/42] de los encuestados opinan que el modelo sanitario catalán es exportable siempre y cuando el país que lo adopte sepa adaptarlo a su realidad histórica y cultural.

Esta pregunta puede parecer en un primero momento fuera de contexto en el estudio hasta ahora presentado, pero tiene una especial relevancia personal para el autor del estudio, visto que en Brasil el actual sistema sanitario pasa por una ola de reformas y que la Generalitat de Catalunya ha mantenido contactos con el gobierno brasileño, así como con varios otros gobiernos de Sudamérica a través del Bando Mundial, para estudiar la posibilidad de implantación en Brasil —y en otros países sudamericanos- del modelo sanitario catalán. 


\subsection{CONCLUSIONES DEL CAPÍTULO}

Un enfoque como el propuesto ${ }^{2}$, basado en elementos agrupados en los entornos científico, tecnológico, productivo y financiero — capítulo 3 de este estudio- y en las relaciones entre dichos elementos, promovidas mediante los actores caracterizados a lo largo del trabajo y los factores de éxito o instrumentos de fomento de esas relaciones, es valido para analizar el Sistema de Innovación, tanto a escala nacional como regional, desde una concepción de la innovación como fenómeno interactivo. Dicho enfoque permite identificar las fortalezas y debilidades del Sistema y proponer actuaciones de políticas de innovación correctoras o impulsoras.

Retomando los objetivos y las primicias generales de este estudio, — explicadas en el resumen y detalladas en el capítulo 3- y que son los siguientes:

- Realizar un inventario de los actores que desempeñan algún papel en el SI-SSPC.

- Establecer una tipología de los actores que permita definir su papel en el modelo de SI-SSPC.

- Analizar para cada grupo de actores las actividades que realizan en el SI-SSPC.

El primero de los objetivos está ampliamente descrito en el capítulo 6, el tercero de los objetivos está estudiado en el capítulo 7, por tanto, queda el segundo de los objetivos del estudio por ser cumplido y es posible ahora establecer una tipología de actor que permite su clasificación de acuerdo con la función que desempeña en el SI-SSPC.

Los grupos de actores identificados en el caso SSPC y con el modelo de sistema de innovación propuesto, son los siguientes:

El entorno científico:

- Hospitales del Grupo 4 o de alta tecnología.

- Grupo ICS.

Entorno tecnológico:

- Hospitales del Grupo 4 o de alta tecnología.

2 Recordamos que Fernández y Conesa [1996, p. 27] explican que se podría incluir también el entorno de los usuarios formado por las personas que finalmente demandan productos o servicios que incorporan tecnología. La consideración de esto quinto entorno en el ámbito de los usuarios debe ir introduciéndose a medida que se vaya desarrollando y organizando suficientemente a través de entidades locales, sindicatos, organizaciones de consumidores, ayuntamientos, ONGs, etc. 
- Grupo ICS.

- Empresas públicas del SCS.

Entorno productivo:

- Hospitales del Grupo 4 o de alta tecnología.

- Grupo ICS.

- Empresas públicas del SCS.

Entorno financiero:

- SCS.

- Regiones sanitarias del SCS.

- Grupo ICS.

Se han identificado 23 actores que han sido adscritos a algunos de los grupos referidos, cada uno de los cuales se caracteriza por los objetivos que persigue, los elementos que relaciona, los instrumentos de relación utilizados y las actividades desarrolladas.

En el entorno científico donde mayoritariamente se producen conocimientos científicos, los actores analizados ejercen su función de dinamización sobre los propios elementos de dicho entorno y con una gran competencia entre ellos. Destacan en solitario los hospitales de alta tecnología — los hospitales de alta tecnología no ICS y los hospitales de alta tecnología del Grupo ICS - por su mayor efecto movilizador y su importante aportación científica al SSPC aunque, en muchos casos la escasez de medios y la falta de apoyo institucional - que deriva y proporciona que este potencial dinamizador vaya hacia la investigación sumergida - impide que realicen un papel más activo.

En el entorno tecnológico donde se desarrollan las tecnologías, nuevamente se destacan los hospitales de alta tecnología - ICS y no ICS — que conforman un grupo muy homogéneo, pero sin duda constituyen junto con algunas empresas públicas - IDI y SSRCTBT - la única vía del sistema hacia la innovación tecnológica. En sus actividades de $\mathrm{I}+\mathrm{D}$ no se aprecian los componentes movilizadores de investigación cooperativa con los demás actores del sistema. Las empresas públicas del entorno tecnológico — IES y AATMcon mayor implicación en áreas de formación de personal de los demás actores y de información técnica —especialmente la AATM - tienen un carácter difusor amplio.

En el entorno productivo donde se producen bienes y servicios, los actores implicados — hospitales de alta tecnología y empresas públicas - son los mismos que generan la tecnología y la investigación científica del sistema favoreciendo de esa manera los procesos de innovación del sistema, lo que nuevamente queda evidente es 
la falta de los componentes movilizadores o factores de éxito como puede ser la red cooperativa y la gestión de la innovación en el ámbito del sistema.

En el entorno financiero que es el que ofrece recursos económicos a los demás entornos encontramos el SCS como comprador-planificador y a la vez proveedor del sistema y las regiones sanitarias como actores descentralizados del SCS en la totalidad del territorio catalán. El ICS también juega un papel decisivo en este entorno — teniendo su presupuesto aprobado directamente por el Parlament de Catalunya- como mayor proveedor de servicios sanitarios del sistema independiente de recibir los traspaso financiero desde el SCS. En general, este entorno realiza un papel — papel de presión hacia los demás actores- muy escaso como comprador único de los servicios sanitario del sistema, presión esta que podría fomentar los componentes movilizadores y los factores de éxito para que se extendiesen en las escasas relaciones desarrolladas por los actores del sistema.

La distribución geográfica de los actores del SI—SSPC es muy desigual. La región metropolitana de Barcelona concentra el 78,2\% [18/23] de los actores del sistema estudiados lo que pone en riesgo la equidad territorial y posibilidad de acceso de los usuarios a todos los servicios sanitarios principalmente a los de alta tecnología, independiente del trabajo que ha hecho el SCS para que esta realidad no se acentuara, los hospitales del Grupo 1 son el ejemplo de este esfuerzo del SCS en la equidad y accesibilidad del SI—SSPC.

En conjunto el perfil de los actores muestra un SI-SSPC débilmente articulado que puede disponer de su entorno científico para participar en los procesos de innovación que hoy se precisan, pero que todavía dispone de unos entornos que no se relacionan, limitando la difusión de la información y los procesos de innovación. Asimismo, el sistema está limitado y desequilibrado, pues los actores se concentran en la cuidad de Barcelona, y se encuentra poco maduro al encontrarse muy condicionado por el papel de la administración -las subvenciones - y por la ausencia de los elementos dinamizadores o factores de éxito que podrían jugar un papel decisivo en el impulso del sector hacia el SI.

Analizando de manera más detallada las relaciones de los hospitales de alta tecnología [por ser el actor que más I+D aporta al sistema] vemos que las relaciones existentes entre éstos actores son muy escasas como ya se a dicho anteriormente y, se expresan en la figura 7.1:

El SCS — flechas de color negro—- mantiene relaciones directas con las regiones sanitarias RSBC y RSCP y con el ICS. También mantiene relaciones de manera más informal, pues las relaciones normales deberían darse a través de la región sanitaria —flechas de color negro punteadas - con todos los hospitales del Grupo 4. 
El ICS mantiene relaciones con sus hospitales —flechas de color azul- y también mantiene relaciones con el SCS — flecha de color negro- y con las regiones sanitarias — flechas de color azul— donde están ubicados sus hospitales.

La RSBC mantiene relaciones — flechas de color verde_ con los hospitales del Grupo 4 ubicados en su territorio. También mantiene relaciones con el SCS —flecha de color negro—, con la RSCP —flecha de color negro trazo/puntoy con el ICS — flecha de color azul-.

La RSCP mantiene relaciones — flechas de color rojo- con los hospitales del Grupo 4 ubicados en su territorio. También mantiene relaciones con el SCS —flecha de color negro—, con la RSCP — flecha de color negro trazo/punto— y con el ICS — flecha de color azul-.

FIGURA 7.1. Relaciones existentes.

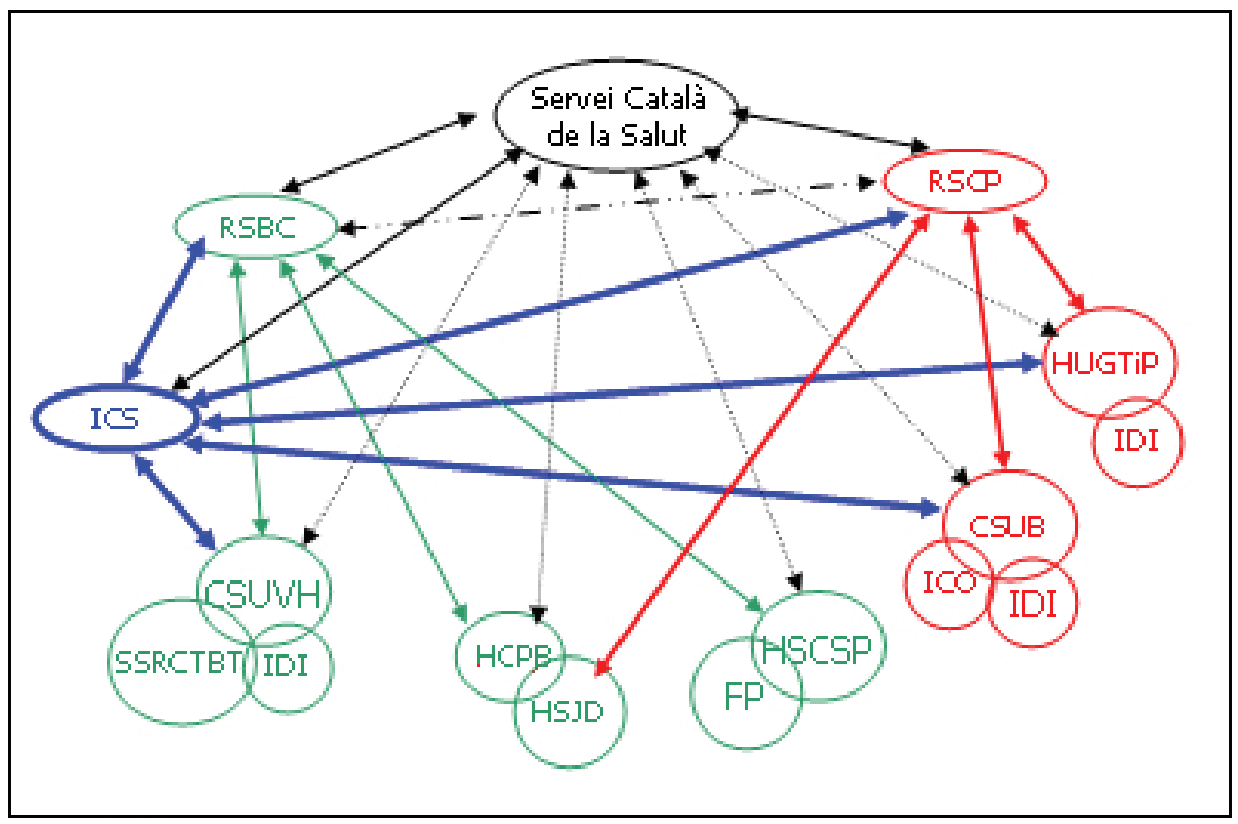

Fuente: Elaboración propia.

Pero las relaciones que deberían existir, además de las que hemos comentado, se dibujan en la figura $7.1 \mathrm{y}$ son las siguientes:

Las flechas de color naranja intentan dibujar una estructura matricial de relación-cooperación entre los hospitales de alta tecnología del SI-SSPC.

Las relaciones existentes entre estos actores son muy informales y dependen más de las relaciones personales de los médicos, jefes de equipos y gerentes de 
uno u otro centro que de las relaciones instituciones de cooperación que pudiera existir.

Las relaciones que sí son formales, son las expresadas por los círculos que se sobreponen entre sí. La CSUVH tiene relaciones fuertes con el IDI y con SSRCTBT, pues son dos EP que nacieron de la estructura de la CSUVH y están ubicadas en su entorno hospitalario. El IDI está en fase de firmar convenios o contratos de cooperación y trabajo con el HUGTiP y con la CSUB. El HC tiene firmado convenio y contrato de cooperación y trabajo con el HSJD.

FIGURA 7.2. Relaciones que deberían existir.

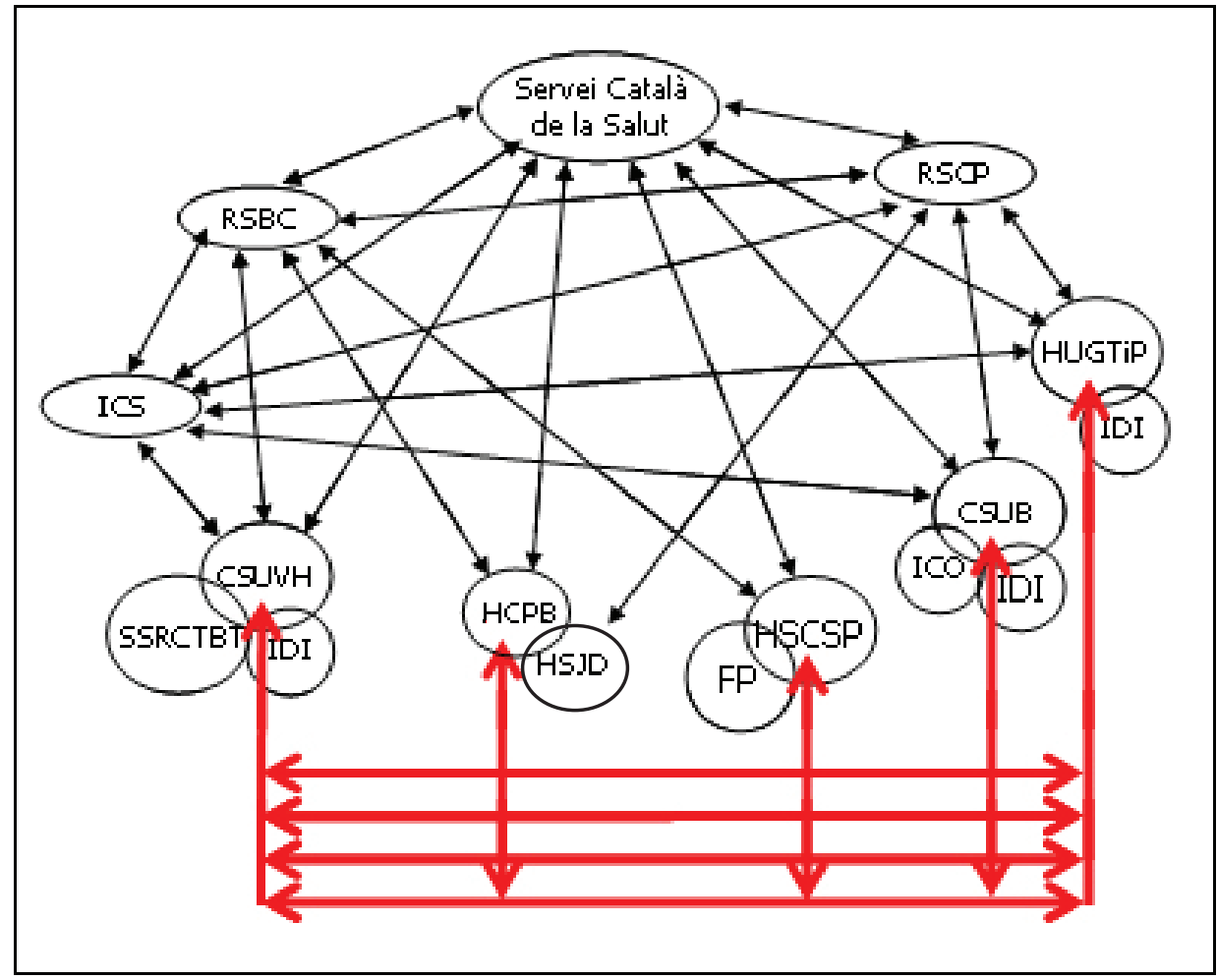

Fuente: Elaboración propia.

El HSCSP tiene firmado convenio y contrato de cooperación y trabajo con la FP. La CSUB tiene firmado convenio y contrato de cooperación fuerte con el ICO, pues éste es una EP que nació de la CSUB y está ubicado en su entorno hospitalario. El HUGTiP está por firmar el convenio y contrato de cooperación y trabajo con el IDI. 
En conclusión, las relaciones matriciales de cooperación entre los hospitales de alta tecnología no existen o en caso de existir alguna relación, éstas son personales e informales. Si estas relaciones existiesen, a falta de estudios económicos detallados de los costes de las estructuras verticalizadas, se puede decir que se podría horizontalizar estructuras que hoy están duplicadas, triplicadas o verticalizadas en cada entorno hospitalario y de esa manera tender a reducir costes y adecuar las plazas o camas de alta tecnología a las necesidades reales del SSPC.

Las EP como el SSRCTBT, ICO y el IDI tienen como misión ser referencia para toda Catalunya, son por lo tanto empresas que podrían asumir las estructuras de los hospitales de alta tecnología que están ubicados en un radio de distancia pequeño, excepción del HUGTiP los demás están ubicados en Barcelona y su área metropolitana.

El DSSS ha impulsado y potenciado la constitución y creación de diversas fundaciones para la gestión económica y administrativa de la investigación científica, vinculadas a los hospitales de alta tecnología gestionados por el ICS. También han constituido fundaciones los hospitales HC y HSCSP.

La tabla 7.69 muestra una comparación entre los principales indicadores de los hospitales de alta tecnología del SSPC.

TABLA 7.69. Comparación entre los principales indicadores asistenciales de los hospitales de alta tecnología 1997.

\begin{tabular}{|c|c|c|c|c|c|c|c|c|}
\hline $\begin{array}{l}\text { Hospital } \\
\text { Indicador }\end{array}$ & ICO & FP & CSUB & HUGTIP & $\mathrm{HC}$ & HSJD & HSCSP & CSUVH $^{1}$ \\
\hline $\begin{array}{l}\text { Número de } \\
\text { ingresos }\end{array}$ & 3838 & 5426 & 26085 & 18110 & 36793 & 19083 & 27097 & 53904 \\
\hline $\begin{array}{l}\text { Número de } \\
\text { altas }\end{array}$ & 3832 & 5349 & 26158 & 18141 & 34874 & 10898 & 27097 & 55726 \\
\hline $\begin{array}{l}\text { Número de } \\
\text { camas }\end{array}$ & 118 & 165 & 847 & 565 & 852 & 335 & 723 & 1443 \\
\hline Estancia media & 8,99 & 6,92 & 11,2 & 10,4 & 7,59 & 5,24 & 9,08 & 8,04 \\
\hline Ocupación \% & 81,50 & 70,15 & 95 & 91 & 89,80 & 80,54 & 93,30 & 86,67 \\
\hline $\begin{array}{l}\text { Rotación } \\
\text { enfermo/cama }\end{array}$ & 32,51 & 38,23 & 31 & 32 & 43,23 & 59,08 & 37,5 & 37 \\
\hline Urgencias & 165 & 16398 & 100158 & 98633 & 134427 & 103068 & 123287 & 220167 \\
\hline $\begin{array}{l}\text { Intervenciones } \\
\text { quirúrgicas }\end{array}$ & 11596 & 4000 & 21434 & 9404 & 17424 & 11153 & 17278 & 42557 \\
\hline
\end{tabular}

Fuente: Elaboración propia. 
En esta tabla se percibe, por el porcentual de ocupación, la existencia de un exceso de plazas o camas de alta tecnología en el SSPC, y los hospitales de alta tecnología no tienen interés en horizontalizar las estructuras pues de esa manera algunos de ellos podrían perder la clasificación de pertenecientes al Grupo 4 y perderían así las subvenciones que aporta el SCS a esos centros. 
